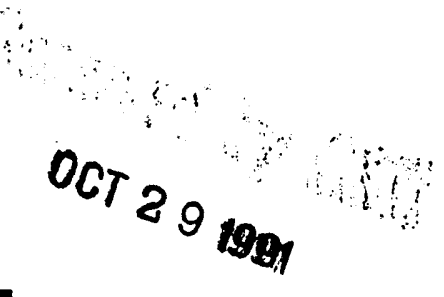

\title{
A Limited Human Factors \\ Engineering Assessment of the 242-A Evaporator System: For Input to the Safety Class II Systems/Structure Assessment
}
A. Schur
S. T. Hunt
D. J. Pond

October 1991

Prepared for the U.S. Department of Energy under Contract DE-AC06-76RLO 1830

Pacific Northwest Laboratory

Operated for the U.S. Department of Energy by Battelle Memorial Institute 


\section{DISCLAIMER}

This report was prepared as an account of work sponsored by an agency of the United States Government. Neither the United States Government nor any agency thereof, nor Battelle Memorial Institute, nor any of their employees, makes any warranty, expressed or implied, or assumes any legal liability or responsibility for the accuracy, completeness, or usefulness of any information, apparatus, product, or process disclosed, or represents that its use would not infringe privately owned rights. Reference herein to any specific commercial product, process, or service by trade name, trademark, manufacturer, or otherwise does not necessarily constitute or imply its endorsement, recommendation, or favoring by the United States Government or any agency thercol, or Battelle Memorial Institute. The views and opinions of authors expressed hercin do not necessarily state or reflect those of the United States Government or any agency thereof.

\section{PACIFIC NORTHWEST LABORATORY operated by \\ BATTELLE MEMORIAL INSTITUTE for the \\ UNITED STATES DEPARTMENT OF ENERGY under Contract DE-ACO6-76RLO 1830}

Printed in the United States of America

Available to DOE and DOE contractors from the

Office of Scientific and Technical Information, P.O. Box 62, Oak Ridge, TN 37831; prices available from (615) 576-8401. FTS 626-8401.

Available to the public from the National Technical Information Service, U.S. Department of Commerce, 5285 Port Royal Rd., Springfield, VA 22161. 
PNL --7806

DE92 001994

A LIMITED HUMAN FACTORS ENGINEERING

ASSESSMENT OF THE 242-A EVAPORATOR SYSTEM:

FOR INPUT TO THE SAFETY CLASS II

SYSTEMS/STRUCTURE ASSESSMENT
A. Schur
S. T. Hunt
D. J. Pond

October 1991

Prepared for

the U.S. Department of Energy

under Contract DE-ACO6-76RLO 1830

Pacific Northwest Laboratory

Richland, Washington 99352

\section{MASTER}

nISTRIBidTiON OF THIS DOCUNENT IS UNLIMITED 


\section{EXECUTIVE SUMMARY}

A time-limited human factors engineering (HFE) assessment was conducted of the software, hardware, and facilities related to the items in the 242-A Evaporator Safety Class II Systems/Structures. The purpose of this assessment was to determine, prior to the startup of the Evaporator system, the adequacy of the controls and monitors in ensuring safe operations. The results of this assessment are described in this report.

The assessment was conducted by professional human factors engineering staff who are experienced in the evaluation and development of supervisory control and monitoring systems used for process control. Information was collected primarily through interviews with and observations of experienced Evaporator operators. Because implementation of the Monitor and Control System (MCS) is the dominant change in Evaporator operations, the human factors assessment focused primarily on the MCS. Particular attention was directed toward the operator's ability to access information and to correctly and quickly interpret such information. Additionally, the consistency and appropriateness of terminology and symbology used throughout the system were areas of special concentration.

The assessment was performed in the absence of a fully defined operational framework. There were three contributing factors: 1) revisions of the MCS were still in progress, 2) the MCS development and refinement occurred in the absence of a baseline concept of operations, 3) the impact of operator training on the operations of the Evaporator could not be evaluated because operators had not yet received training.

Although the circumstances in which the MCS was assessed did not provide a fully defined operational framework, it was still possible to evaluate the requisite system parameters based on general principles of Evaporator operation and good human factors engineering principles. The accuracy, adequacy, and appropriateness of the following assessment and recommendations can be expected to increase as more system definition is achieved (especially as information from human factors/systems analyses is incorporated into the system definition and refinement process.) 
From this assessment, it is apparent that the safe, efficient operation of the 242-A Evaporator system is paramount in the minds of management, operators, and technical support personnel. Evaporator hardware and software design features do reflect this perspective and, as a result, the system has "user friendly" qualities for providing an operator interface for controlling and monitoring the Evaporator system.

Many of the items in this report may stem from Evaporator system development apparently occurring in the absence of a well-defined "Concept of Operations" or the limitations of the Texas Instruments Development Tool used to implement the MCS. Additionally, it appears that on-the-job training is relied on quite heavily to define operator roles as well as to overcome design shortcomings.

Overal1, it is recommended that system managers, operators, developers, trainers, and human factors experts jointly develop a Concept of Operations document. This document should provide a systematic means to implement changes, develop training programs, operationally test and evaluate the recommended changes, and define requirements for anticipated system upgrades. 
EXECUTIVE SUMMARY ............................ . . . . . . . . . . . . . . .

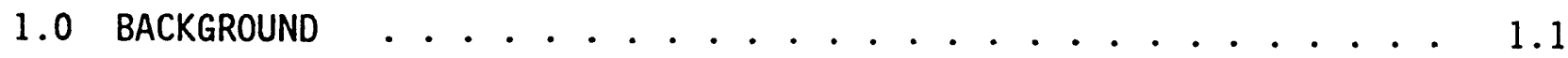

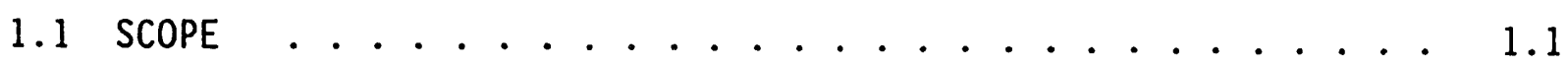

1.2 LIMITATIONS . . . . . . . . . . . . . . . . 1.2

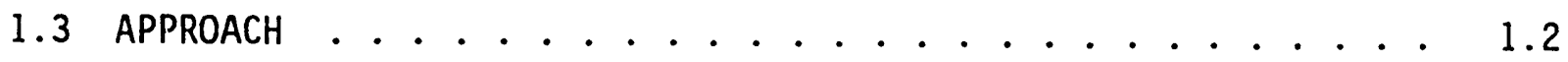

1.4 RESULTS . . . . . . . . . . . . . . . . . . . 1.3

1.5 REPORT ORGANIZATION . . . . . . . . . . . . . . . . 1.4

2.0 CONTROL CONSOLE/ROOM CONFIGURATION . . . . . . . . . . . . . 2.1

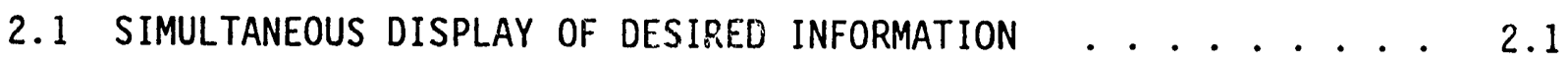

2.2 INCOMPLETE OVERALL EVAPORATOR SYSTEM STATUS REPRESENTATION • • 2.1

2.3 LACK OF DESIGNATED ALARM LIST MONITOR . . . . . . . . . . . 2.2

2.4 LACK OF A MEANINGFUL ANNUNCIATOR PANEL LAYOUT . . . . . . . . 2.2

2.5 LACK OF EVAPORATOR KILL BUTTON . . . . . . . . . . . . . 2.3

3.0 COLOR CODING . . . . . . . . . . . . . . . . . . . . 3.1

3.1 INCONSISTENT USE OF COLOR . . . . . . . . . . . . . . . 3.1

4.0 DATA DISPLAY . . . . . . . . . . . . . . . . . . . . 4.1

4.1 INCOMPLETE SYSTEM REPRESENTATION OF RADIATION DETECTORS $\quad$. 4.1

4.2 LACK OF ALARM LIST DISPLAY TITLES . . . . . . . . . . . . . . 4.1

4.3 LACK OF ALARM LIST COLUMN LABELING . . . . . . . . . . . . . . 4.2

4.4 AMBIGUOUS SCALING OF GRIDS ............... . . 4.2

4.5 AMBIGUOUS MARKINGS ON GRIDS ............... . . . 4.2

4.6 LACK OF DIRECT INFORMATION ACCESS . . . . . . . . . . . . . 4.3

4.7 AMPIGUOUS USE CF GRID GRAPHICS . . . . . . . . . . . . . 4.4

4.8 CLUTTERED DISPLAYS . . . . . . . . . . . . . . . . . . 4.4 


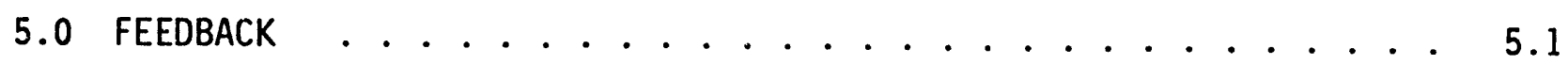

5.1 UNINTENTIONAL DISABLING OF ALARMS . . . . . . . . 5.1

5.2 LACK OF VALVE-OPENING INFORMATION .............. 5.1

5.3 SAME KEY USED FOR CONFIRMING MCS COMMANDS ........ 5.1

6.0 INTERACTIVE CONTROL/SYSTEM NAVIGATION . . . . . . . . . 6.1

6.1 SLOW SYSTEM RESPONSE TIME ................ 6.1

6.2 INADEQUATE INDICATION OF SCREEN HIERARCHY . . . . . . . 6.1

6.3 INADEQUATE INDICATION OF INTER-SCREEN RELATIONSHIPS . . . . 6.2

6.4 INCONSISTENT SCREEN NAVIGATION COMMANDS . . . . . . . . 6.3

7.0 LABELING . . . . . . . . . . . . . . . . . 7.1

7.1 INCONSISTENT DISPLAY NUMBERING . . . . . . . . . . . 7.1

7.2 UNCLEAR LABELING OF ALARM LIST ACCESS BUTTONS . . . . . . 7.1

7.3 MULTIPLE NAMES FOR SPECIFIC ITEMS . . . . . . . . 7.2

7.4 INCONSISTENT USE OF LABELS . . . . . . . . . . . 7.3

7.5 INCONSISTENT LOCATION OF SCREEN TITLES . . . . . . . . 7.3

8.0 General atTRIBUTES . . . . . . . . . . . . . . 8.1

8.1 DISTRIBUTION OF SYSTEM INFORMATION ............... 8.1

8.2 INADEQUATE OPERATOR KNOWLEDGE OF SYSTEMS INTERLOCKS .... 8.1

8.3 TRAINING APPROACH AND ADEQUACY . . . . . . . . . . 8.2

8.4 LACK OF DIAGNOSTIC AIDS . . . . . . . . . . . . . . 8.2

8.5 SIMULTANEOUS TASK REQUIREMENTS . . . . . . . . . . . 8.3

8.6 ABSENCE OF REMOTE DETECTORS ON EXHAUST FILTERS . . . . . . . 8.4

8.7 LACK OF TOXIC LEAK DETECTION MONITORS . . . . . . . . . . . 8.4

8.8 COMPLEX PROCESSES REQUIRED TO FIND SOME SPRAY LEAKS . . . . . 8.5

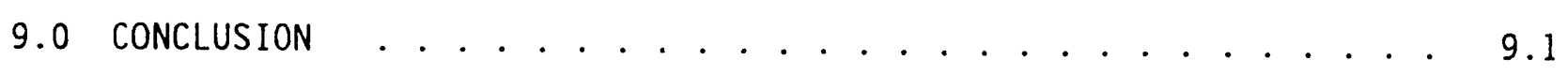

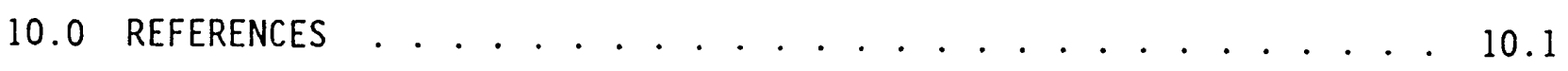


APPENDIX - TABLES ........................ A.1 


\subsection{BACKGROUND}

Prior to the startup of the 242-A Evaporator system, members of the Pacific Northwest Laboratory (PNL) Human Factors Engineering staff conducted an assessment of the controls and monitors related to the issues classified as Safety Class II Systems/Structures. The purpose of this assessment was to determine the adequacy of the controls and monitors in ensuring safe cperations of the Evaporator system, and the results were described in a Letter Report dated Apri1 5, 1991. The ensuing comments/recommendations of Westinghouse Hanford Company operations, safety, and management personnel formed the basis of additional human factors activities that resulted in this report.

\subsection{SCOPE}

A time-limited human factors engineering (HFE) assessment was conducted of the software, hardware, and facilities related to the items in the 242-A Evaporator Safety Class II Systems Structure Table. The areas of concern specified in the Statement of Work for this effort were:

- The adequacy of the monitoring system displays that enable the operator to determine:

- the current status of each safety class system/structure

- whether the desired equipment response occurred for a given command

- actions taken by the system.

- The ability of the operator to initiate response actions based on the information presented via monitoring system displays.

- The adequacy of the alarms with respect to:

- the presence of alarms for each safety class system/structure

- enabling the operator to determine system/structure status

- enabling the operator to determine the appropriate response.

- The suitability of the arrangement of system alarms and monitors in support of timely operator responses to unsafe conditions. 
- The accessibility to operators of manual controls for the safety systems.

- The adequacy of direct feedback to the operator at the location of the manual controls indicating that the correct action has occurred.

\subsection{LIMITATIONS}

The assessment and subsequent recommendations were iimited by the following three critical factors:

1. Revisions to the Monitor and Control System (MCS) continued even as the human factors assessment was performed.

2. Development and refinement of the MCS was accomplished without a baseline "Concept of Operations" through which to define the role and number of operators as well as the interaction of such operators with the MCS. (Briefly, such a Concept of Operations defines how all system elements-hardware, software, personnel, maintenance, procedures, training, etc.-interact throughout the entire life cycle of the system. It also defines what kinds of information should be presented to the operator and how the operator works with and controls the information presented).

3. The impact of operator training on the Evaporator system safety and effectiveness couid not be evaluated because operators had not yet received formal training, but relied upon on-the-job experience.

Although these factors made it difficult to fullv define the operational framework, it was still possible to evaluate the requisite system parameters based on general principles of Evaporator operation and good human factors engineering practices. The comprehensiveness of the following assessment and recommendations can be expected to increase as more system definition is achieved--especially as information from human factors/ systems analyses is incorporated into the system definition and refinement process.

\subsection{APPROACH}

This assessment was conducted by professional human factors engineering staff who are experienced in the evaluation and development of supervisory control and monitoring systems used for process control. Information was collected primarily through interviews with and observations of experienced Evaporator operators. 
The Evaporator control system items specified in the 242-A Evaporator Safety Class Systems Structure Table were analyzed using the design principles set forth in standard human factors gu'deline documents (e.g., NRC 1981, DOD 1989, and Smith and Mosier 1986). Particular attention was directed toward the operator's ability to access information and to correctly and quickly interpret such information. Additionally, the consistency and appropriateness of terminology used throughout the system were of special concentration.

Although the entire Evaporator is being upgraded, approximately $80 \%$ of the changes are associated with the control room. Because the implementation of the MCS system is the dominant change in Evaporator operations, and since software changes are often easier to make and have more widespread system impact than do local hardware modifications, the human factors assessment focused primarily on the MCS.

Three system operators were interviewed. None had yet acquired actual operating experience with the system as currently configured, and only one had received formal training on the Texas Instruments software package used to implement the MCS. One operator was interviewed about the operational significance of the items specified in the Safety Table, and two were interviewed about the use of the MCS. In addition, two MCS software engineers were interviewed with regard to the functionality and structure of the MCS.

\subsection{RESULTS}

Overal1, based un the limited review performed, the MCS prototype appears to provide an easy-to-use interface for controlling and monitoring the Evaporator system. In this regard, the following design attributes are particularly noteworthy:

- use of redundant coding (color and shape) to enhance the readability of the system displays

- use of status panels to indicate the overall status of critical aspects of the Evapoiator system

- provision of multiple methods for accessing Evaporator system information. 


\subsection{REPORT ORGANIZATION}

The system was assessed according to the following areas of design: Control Console/Room Configuration, Color Coding, Data Display, Labeling, Feedback, Interactive Control/System Navigation, and General Sÿstem Attributes. As a result of the assessment, specific human factor items were identified. Each item was categorized with respect to the identified design areas. These items are summarized in two tables in the appendix. Table A.l in the appendix associates related items with the components specified in the Evaporator Safety Class 2 Systems and Structure Table. Table A.2 in the appendix identifies each item's impact on an operator's ability to control and monitor the Evaporator with respect to the concerns specified in the Statement of Work.

Several items appear to impact the Texas Instruments (TI) hardware and software package used to implement the MCS. These items have been identified in the report and include:

- 4.2 Lack of Alarm List Display Tities

- 4.3 Lack of Alarm List Column Labeling

- 4.4 Ambiguous Scaling on Grids

- 4.5 Ambiguous Markings on Grids

- 5.3 Same Key For Confirming MCS Commands

- 7.2 Unclear Labeling of Alarm List Access Buttons.

It is understood that immediate resolution of these items may be infeasible due to the limitations of the Texas Instruments software and hardware capabilities. Therefore, it is recommended that each of these items be addressed during the next planned software system upgrade.

Finally, because of the constraints of the current assessment, it may be beneficial to re-evaluate all items once the recommendations have been implemented to determine if the modifications have fully accomplished the desired results. 


\subsection{CONTROL CONSOLE/ROOM CONFIGURATION}

\subsection{SIMULTANEOUS DISPLAY OF DESIRED INFORMATION}

Four MCS work stations are located (without specifically designated positions: in the Evaporator system control work area. All four work stations are not always in use. Operators take advantage of a "free" work station and use two displays simultaneously to more effect:vely monitor the Evaporator system status. The ability to simultaneously view information could enhance operator/system effectiveness in terms of safety and efficiency.

\section{Example}

Typically, when operators are examining a certain component of the system, they display the schematic graphic of the component on one screen and the associated faceplate display on another screen.

\section{Recommendation}

Perform an analysis to determine the optimal configuration of existing hardware to provide safe, timely, and effective information presentation and system control. For example, design approaches that might be evaluated include 1) redesigning the MCS console as a suite incorporating two display monitors that can be controlled by the operator via a single keyboard, or 2) providing a monitor and keyboard to support process control with other monitors dedicated to displaying monitoring functions. Either of these design options would permit simultaneous ust of different types of display screens as desired by system operators and, if designed and implemented properly, could enhance operator/system effectiveness without adversely affecting system efficiency or safety.

\subsection{INCONPLETE OVERALL EVAPORATOR SYSTEM STATUS REPRESENTATION}

Operators expressed concern that the new system, unlike the old control and monitoring system, does not provide a method for quickly and effectively ascertaining the general status of the Evaporator. This could imact the operator's ability to correctly determine plant status. 


\section{Example}

The old system provided the ability to immediately assess the current status by glancing at the hardware panels. These panels do not exist in the new system, and the operators must call up a series of display screens to gather the information that was previously available at a glance.

\section{Recommendation}

Provide the ability to perform quick overall system status checks using appropriate summary displays. This must be accomplished judiciously since display screens can easily become cluttered with too much, or with improperly presented, information. Display clutter could impair an operator's ability to quickly and correctly determine plant status.

\subsection{LACK OF DESIGNATED ALARM LIST MONITOR}

When more than one monitor is available, operators configure the monitors such that one monitor is devoted to displaying alarm lists while another monitor is used to access specific information. As events occur, the alarm 1 ist monitor is constantly consulted. This configuration allows the operators to quickly identify new alarms without disrupting their current work, thereby aiding diagnosis of events in a more timely, systematic manner and reducing the potential for human error.

\section{Example}

When responding to an alarm, operators often display the alarm list on one screen and the alarm location on another screen.

\section{Recommendation}

Consider MCS console redesign to permit inclusion of a monitor dedicated exclusively to the display of alarm.lists. Such a dedicated monitor could help minimize operator information processing and response times to alarms.

\subsection{LACK OF A MEANINGFUL ANNUNCIATOR PANEL LAYOUT}

The arrangement of the access buttons on the annunciator panel does not reflect a design strategy based on Evaporator operations or physical layout. 
Instead, the access buttons appear to be organized in the order that their associated graphics screens were created. As a result, operators often spend time looking for specific access buttons in a random search pattern. By placing the annunciator buttons according to a logical scheme apparent to the operators, time could be saved in both information retrieval and in training since the operators would be able to intuit the location of a button by having knowledge of the type of information it accesses (and vice versa).

\section{Example}

See Observation above.

\section{Recommendation}

Develop a logical method (based on sequence of use, sequence of signal detection, criticality of operation, simiiarity of function, etc.) for positioning annunciator buttons so that the location is inherently meaningful to the operators.

\subsection{LACK OF EVAPORATOR KILL BUTTON}

During specific critical conditions, it may be appropriate for the operator to initiate an emergency shutdown of the system. The work environment does not provide a hardwired Evaporator "kill button" that enables emergency shutdown to be initiated by the operator. Such a control must be designed to allow quick access while precluding accidental activation.

\section{Example}

See Observation above.

\section{Recommendation}

Consider the installation of an evaporator kill button to permit the operator to initiate shutdown of the system in the event of an emergency. 


\subsection{COLOR CODING}

\subsection{INCONSISTENT USE OF COLOR}

Color is used throughout the 242-A Evaporator system to convey certain meanings, but it is not used consistently. One color may be used to indicate different meanings on different screens, or a particular system state may be conveyed by different colors. This inconsistency has the potential to cause the operator to misinterpret information and/or fail to detect changes when monitoring the system or responding to alarms. Such misuse of color can contribute to the cluttered appearance of display screens which can, in turn, increase the time needed by an operator to find and respond to important information. The inconsistent use of color can also make system navigation more difficult.

\section{Examples}

Indication of Valve State. On the Evaporator Overview display, blue text is used to indicate both the open and closed state of a valve. In the Process Condensate (Screen 018), the closed position for pump PB-1 is indicated by green or white text, while on the Overview Evaporator (Screen 040) white or blue is used.

Indication of Flows. On the Vaculim Condenser (Screen 016) colors are assigned the following meanings: white represents condensate flow, dark biue represents water, and light blue represents steam. Colors are displayed on the Evaporator Overview (Screen 040) with the following relationships: white represents venting, dark blue represents water, yellow represents steam, 1 ight blue represents process flow, and green represents air.

Multiple Meanings Assigned to a Single Color. Yellow is used both to signify that alarms are non-critical and that alarms are inhibited. White text is used both for system coriponent titles (along with light blue) and flow levels. (For an example of this refer to Screen 012 in the system.) Red is used both to indicate that a system (such as a pump, tank, or valve) is active or open as well as to indicate that a systen is in an alarm state. 
Numbered Boxes for System Navigation. Purple and white boxes around numbers are used to indicate quick access numbers to graphic screens and faceplates.

Open-to-Close Valves. Open-to-Close values are represented in blue text on the schematic graphics and in green text on the faceplates.

Recommendation

Develop a consistent color scheme (compliant with appropriate specification documents such as NRC 1981) and apply it to all labeling and graphics screens throughout the MCS. 


\subsection{DATA DISPLAY}

\subsection{INCOMPLETE SYSTEM REPRESENTATION OF RADIATION DETECTORS}

The operators suggested that the radiation detectors' alarm limits should be shown when the count is approaching a critical level. Currently, operators must remember the limits. Appropriate display of the critical limits could improve their operational performance by minimizing the need to rely on the operator's memory to correctly interpret the displayed information.

\section{Example}

The system only indicates radiation levels through the presence or absence of alarms.

\section{Recommendation}

Indicate the radiation count in such a manner that it is possible for the operator to determine the current count in relation to critical limits.

\subsection{LACK OF ALARM LIST DISPLAY TITLES}

There are four al arm categories within the system: P1 (critical Evaporator Alarms, also called "red alarms"), P2 (non-critical Evaporator Alarms al so called "yellow alarms"), P3 (MCS system state alarms), and White Alarms (non-critical general system alarms). When an alarm list is displayed for one of these classes, the user does not alwavs receive labeled information indicating the class of alarm. This could ciluse the operator to misinterpret the information displayed and to respond in a less timely manner to the alarm condition.

\section{Example}

The P2 alarm screen title does not state "Non-Critical Alarms."

\section{Recommendation}

Provide alarm list titles that indicate the type of alarms being displayed that correspond to the labels used on the alarm access buttons. 


\subsection{LACK OF ALARM LIST COLUMN LABELING}

The columns on the alarm list display screens are not labeled. Appropriate labeling can help minimize the potential for misinterpretation and ambiguity. For example:

$\frac{\text { Date }}{03 / 29 / 91} \quad \frac{\text { Time }}{01: 12: 33} \quad \frac{\text { Location }}{\text { PN6 }} \quad \frac{\text { Descriction }}{\text { Process Condensate }} \quad \frac{\text { Status }}{\text { Stable }}$

\section{Example}

The red, yellow, and white alarm lists are not labeled.

\section{Recommendation}

Label alarm list columns with respect to the information displayed and its function during the next planned software system upgrade.

\subsection{AMBIGUJOUS SCALING OF GRIDS}

Grid scaling does not always match that of the hardware being represented. Further, scaling levels on some grids make it difficult to discriminate a low level of flow from no flow at all. This could cause the operator to misinterpret the information displayed.

\section{Example}

This mismatch can be observed when the flow level is extremely low on faceplates 11-AW-102 and CI-WVR-1.

\section{Recommendation}

Ensure that all grids are scaled so that the status of the flow is obvious and that the full range of flows is effectively presented to the operator.

\subsection{AMBIGUOUS MARKINGS ON GRIDS}

Several of the faceplate flow grids contain red marks to indicate either the maximum possible flow or the level of flow at which a critical alarm is triggered. It is not obvious whether a red mark indicates the maximum flow or 
the alarm level. Ambiguous markings can cause misinterpretation of infurmation which in turn could result in the operator taking inappropriate corrective actions.

\section{Example}

Screen 41 contains several grids with red lines indicating either maximum flow levels or alarm levels.

\section{Recommendation}

During the next planned software system upgrade, eliminate any ambiguity in the markings or symbols on the system displays by appropriate use of color coding and/or labeling.

\subsection{LACK OF DIRECT INFORMATION ACCESS}

Accessing information often requires a series of two or more button presses rather than a single action. During critical times such as periods of multiple alarms and acknowledgments, such multiple steps could hinder access to information. The potential for such delay is compounded by the lack of navigation and orientation cues (see items 6.1 to 6.4 ).

\section{Example}

In the event of a tank farm alarm, there is no way to immediately identify where the alarm occurred. It is sometimes necessary to access multiple display levels to acquire needed information. This is in contrast to the old system in which each tank farm had its own hardware panel and the operator had only to glance at the panel to find the location of the alarm.

\section{Recommendation}

Perform an analysis to determine when certain information should be directly accessible to the operator. This analysis would assist in the determination of appropriate direct access techniques. It is not necessary to make all of the information in the MCS system directly accessibie all the time. However, information that is determined to be of a critical nature at certain times should be made directly accessible during those times to ensure a timely response by the operator. 


\subsection{AMBIGUOUS USE OF GRID GRAPHICS}

Grid graphic display formats are used to display two kinds of information: summary system process information and detailed information regarding specific components of the system process. These two types of information are not always clearly differentiated, and the operator could, therefore, mistakelliy interpret summary data as detailed information, or vice versa. This potential is heightened if the operator is performing general status checks of the grid flows and, therefore, not reading the associated grid text.

\section{Example}

See Observation.

\section{Recommendation}

Clearly differentiate grid graphics according to their display function.

\subsection{CLUTTERED DISPLAYS}

Many of the displays are visually cluttered. Contributing factors include the use of a single color to convey many different kinds of isformation (see item 3.1), the portrayal of a great deal of information on a single display, and the interference caused by the location of the screen title and screen ID relative to the infoimation displayed on the screen. As a result of such screen clutter, operators often find it difficult to locate the needed information on a screen. This could negatively impact a timely response to the noted system condition.

\section{Example}

The Process Condensate (018) display contains all three problems cited above.

\section{Recommendation}

Implement any of the following recommendations to reduce clutter or judiciously implement all three to minimize the potential for adverse impacts due to screen clutter: 1) reduce the amount of information displayed by placing more of the detailed information in lower level displays; 2) relocate the screen title and screen ID to an area of the screen that is less intrusive 
on the information displayed (note: if this approach is taken, the title and ID should be placed in the same location for all of the screens); 3 ) use color consistently (see item 3.1). 


\subsection{FEEDBACK}

\subsection{UNINTLNTIONAL DISABLING OF ALARMS}

Operators apparently never need to disable alarms and only system engineers use this function. When an operator performs the actions required to inhibit an alarm, the alarm can accidentally be disabled.

Example

The actions for disabling alarms on screen 24 PC-IX Pres, DP demonstrates this observation.

\section{Recommendation}

Eliminate the capability to disable alarms from the operator console.

\subsection{LACK OF VALVE-OPENING INFORMATION}

Valves have four possible physical states (open, closed, opening, and closing), but only three of these states are indicated on the MCS (open, closed, and closing). This does not allow for a complete representation of the Evaporator's status, which could result in the operator misinterpreting the displayed information.

\section{Example}

Valve HV-SC-1B on screen 022 demonstrates this observation.

\section{Recommendation}

Add a representation of the valve "opening" state to the MCS displays.

\subsection{SAME KEY USED FOR CONFIRMING MCS COMMANDS}

The current method for confirming certain commands in the MCS system is to require the operator to issue the same command twice using the same key. An operator might inadvertently activate a command by accidentally pressing the command key twice without intending to or without being aware of having done so. 


\section{Example}

The process for closing a valve demonstrates the current confirmation method.

\section{Recommendation}

During the next planned software system upgrade, establish confirmation commands that differ from initial commands to minimize the potential for accidental issuance of the confirmation command. By making the confirmation input different from the initial input, the operator is forced to become more fully aware of the confirmation action and, therefore, less likely to make an error. 


\subsection{INTERACTIVE CONTROL/SYSTEM NAVIGATION}

\subsection{SLOW SYSTEM RESPONSE TIME}

Slow system response times are frequently noted. This could adversely affect an operator's ability to remember critical information or to maintain attention on a task. This slow system response can be especially disruptive of an operator's cognitive functioning during periods of high stress or during critical system operations.

\section{Example}

To access the lecation of an alarm and establish the function of the alarm, the operator first accesses a graphic display by pressing the flashing button on the annunciator pane1. On the selected graphic, the alarm is highlighted by flashing text. A number located near the flashing text indicates which function key should be pressed to access the relevant alarm list. Should other computations be in progress, or should other operators simultaneously be accessing displays, the display of the requested information may be noticeably slowed.

\section{Recommendation}

Use the opportunity of anticipated system upgrade efforts to establish system response times that are compatible with operator task needs in order to ensure that task performance is not degraded due to slowed system responses.

\subsection{INADEQUATE INDICATION OF SCREEN HIERARCHY}

The current set of graphic and alarm list screens provides little information to the operator regarding the relationships between screens. It is, therefore, often difficult to become orientated to the system (i.e., "know where one is") and to move efficiently (i.e., "navigate") through the system. Operators may become lost within the system structure and not recall which screen was used to arrive at the current display. This can hinder or prevent operators from finding appropriate information and can significantly increase operator response time, training requirements, and probability of error. 


\section{Example}

See Observation.

\section{Recommendation}

Inform operators regarding their location within the system at all times. Techniques that might accomplish this include the development of a graphical representation of the screen hierarchy, appropriate labeling of screens, and/or revising input procedures performed by the operator.

\subsection{INADEQUATE INDICATION OF INTER-SCREEN RELATIONSHIPS}

Screens that are a part of a sequence of screens give no indication that they are a part of the sequence. Also, screens that have sub-screens, which contain additional information, often give no indication that this information exists and, as a result, users may not realize the information is available. In addition, a false impression of the relationship between screens may arise because the sequential order as indicated by the assigned screen IDs does not represent the operational order. The inaccurate representation of relationships between screens in the system can cause users to become disoriented (i.e.,"lose their way") and unable to find appropriate information. A poorly defined inter-screen relationship increases the probability of errors, missed information, longer response times, and greater training requirements.

\section{Example}

Faceplates with more than 16 grids extend over several screens but contain no information indicating the number of total screens or which screen in the sequence is displayed.

\section{Recommendation}

Devise a method to clearly indicate the relationship among screens in the system. Strategies that might accomplish this include improving the screen IDs (see Item 7.1), and labeling screens so that their relationship to other screens is indicated (e.g., "EH-V faceplate screen 1 of 3 "). 


\subsection{INCONSISTENT SCREEN NAVIGATION COMMANDS}

The commands used to navigate through the MCS screen hierarchy are not consistent. Table A.3 in the appendix details different commands used to move from one screen to another. Many of these commands work only for certain screins, although there is often no obvious indication on the screens as to which navigation commands are appropriate. In addition, the use of navigation commands is not consistently linked to the type of screen currently displayed. This system can be confusing and frustrating, especially for less experienced users, and can negatively impact the operator's ability to respond to events in a timely manner.

\section{Example}

See Table A.3 in the appendix.

\section{Recommendation}

Devise a consistent approach to screen navigation and implement it across all categories of displayed information. 


\subsection{LABELING}

\subsection{INCONSISTENT DISPLAY NUMBERING}

Each graphical display is assigned a unique screen identification number or "screen ID." These screen IDs are used by the operator to directly access the screen by typing in the number. However, the ways in which these numbers appear varies, and the numbers seem to be assigned somewhat arbitrarily. These factors can cause the operator to misunderstand how items of information and screens within the system are related, and can also confuse operators about their location within the system.

\section{Example}

On faceplate displays, the screen ID is shown beside the faceplate display titles with no leading zero or parenthesis around the number (e.g., 30 Steam Condensate), while on schematic displays the screen ID is centered below the screen title enclosed in parenthesis with a leading zero shown as Steam Condensate (014).

\section{Recommendation}

Develop a display numbering scheme that promotes formulation of correct relationships between information items and screens, and presents screen IDs in a consistent format. For example, the screen IDs could be assigned so that they indicate both what kind of information a screen contains and where the screen lies within the MCS hierarchy. This shame sho!id be applied consistently to all screens.

\subsection{UNCLEAR LABELING OF ALARM LIST ACCESS BUTTONS}

The access buttons $P 1, P 2$, and $P 3$ are used to access 1ists of specific types of alarms (Pl-critical alarms/red, P2-non-critical alarms/yellow, and P3-system alarms). Since there is no obvious link between the access button label and the type of alarm it represents, users may have difficulty accessing the correct alarm categories thereby increasing the time to respond to an alarm condition. This problem is compounded when combined with the lack of 
alarm list column labeling (see Item 4.2), resulting in the potential for an operator to look at the wrong alarm list in response to an alarm.

\section{Example}

This problem is demonstrated by accessing any one of the alarms lists (red, yellow or system) through use of the P1, P2, or P3 keys.

\section{Recommendation}

During the next planned software system upgrade, give the alarm access buttons $P 1, P 2$, and $P 3$ labels that more meaningfully indicate their alarm type (critical, non-critical, MCS). This practice would be consistent with the scheme used to label the access button for white alarins.

\subsection{MULTIPLE NAMES FOR SPECIFIC ITEMS}

Some items in the MCS are referred to by several different names. In addition, some of the abbreviations used to label parameters in the old and rew system are different even though their meanings are the same. This might cause operators to mistakenly believe that the different names refer to different items or sub-categories of items. This could impact the operator's ability to correctly determine plant status by misinterpreting the displayed information.

\section{Example}

"Critical Evaporator Alarms" are also referred to as "Pl alarms" and "red alarms." The old system used SPG for specific gravity whereas the MCS uses the abbreviation DII for density. These two terms mean the same thing with respect to the parameter value and to the system status.

\section{Recommendation}

Make labeling throughout the system in accordance with ISA standards, and give operators specific training on this labeling scheme. 


\subsection{INCONSISTENT USE OF LABELS}

The closed state of a valve is labeled several different ways, which could cause confusion for operators and impact their ability to take appropriate corrective actions.

\section{Example}

The Evaporator Overview (screen 040) uses the letter "C" to indicate closed and the letter " 0 " to indicate open. For Process Condensate (screen $301)$, the positions are labeled as either Open or Closed.

\section{Recommendation}

Develop a consistent labeling scheme and apply it to all labeling throughout MCS.

\subsection{INCONSISTENT LOCATION OF SCREEN TITLES}

Screen titles, when present, are positioned at different locations on the screen. Additionally, in some cases the title serves both as a display title and as a label for a particular aspect of the graphic. The latter practice is confusing because two different methods are used to title a screen. The differing location makes information hard to find, causes the operator to search the display for information, and adds to the impression that the display is cluttered. This could cause the operator to misinterpret the displayed information and increase the time required to locate information.

\section{Example}

The schematic graphic displays place the screen title in the lower right-hand corner of the display, while the trend displays place the screen title along the $Y$ axis of the trend graph. Additionally, "0" could mistakenly be read as a numeric zero ("0").

Recommendation

Develop a consistent display titling scheme. 


\subsection{GENERAL ATTRIBUTES}

\subsection{DISTRIBUTION OF SYSTEM INFORMATION}

The current method of using both the Computer Automated Surveillance System (CASS) and MCS system could increase operator workload and training requirements. Also, there is the potential for delays in problem identification and timely responses to any given problem due to the lack of immediately available and appropriately integrated information.

\section{Example}

It is necessary to refer to a hard copy printed out by the CASS system in order to monitor Tank Farm liquid levels and line leak detection alarms.

\section{Recommendation}

Incorporate the information from the CASS system into the MCS system.

\subsection{INADEOUATE OPERATOR KNOWLEDGE OF SYSTEMS INTERLOCKS}

Many new interlocks have been installed into the Evaporator system and are presently being incorporated into the MCS. Operators must use past experience and knowledge of the system to gather an overview of interlock operations. This overview does not, of course, include the new interlocks of which the operators are not yet aware. Because the inclusion of new interlocks has only just started and no formal interlock training has yet been received by the operators, it is premature to assess their operational impact with respect to safety.

\section{Example}

See Observation.

\section{Recommendation}

Revisit the impact of interlocks on the safe operation of the Evaporator system as part of the development of an Evaporator system Concept of Operations. A detailed study of the relationship between system interlocks and the displayed information should be performed. 


\subsection{TRAINING APPROACH AND ADEQUACY}

Operators obtain knowiedge of the system through use of the MCS in their daily operations, which do not include operating the Evaporator, participation in MCS software application training courses, and exposure to the MCS system during its development. Formal training program plans or implementation were not available for human factors assessment.

\section{Example}

No operators have received formal training for monitoring the Evaporator via the MCS.

\section{Recommendation}

As far as can be determined, operator training (primarily on-the-jobtraining) is an important remediation strategy for dealing with Evaporator/job design deficiencies. Early development of a comprehensive training program is, therefore, recommended. Note, however, that operator training, in addition to being an expensive process, is considered the least "desirable" of the four approaches to minimizing system hazards (the others, in order of preference, being elimination, protection, and warning--see DOD 1984).

\subsection{LACK OF DIAGNOSTIC AIDS}

The current system is primarily set up to promote the detection of anomalous conditions (e.g., alarm states) and indicate their location. The sj'stem assists the operator in performing rudimentary diagnoses to identify the probable cause of an anomalous condition. However, any diagnostic activity is heavily dependent on the operator's knowledge of the system and the system history that the operator has gained through experience and training.

\section{Example}

See Observation.

\section{Recommendation}

Enhance the system by incorporating features that directly assist the operator in diagnosing the causes of events. This would, in turn, facilitate the performance of appropriate responses to anomalous conditions and would 
improve the operator's ability to identify such conditions earlier, thereby reducing the amount of training and experience required to safely operate the system.

\subsection{SIMULTANEOUS TASK REQUIREMENTS}

When many alarms occur in quick succession, a single operator may be overloaded in terms of his/her ability to respond to the event(s) in a timely and effective manner. The operator may be placed in a situation where it is necessary to simultaneously monitor overall system status, respond to new: al arms, monitor the status of previous alarms and, depending upon the previous alarms status, take appropriate action. This set of operational circumstances could cause the operator to respond inappropriately or perhaps fail to respond to an alarm condition. The inability to simultaneously view summary status display and alarm lists has the potential to exacerbate inappropriate responses by the operator under this set of operational circumstances.

\section{Example}

When an initial alarm occurs, the operator locates the alarm by either accessing the alarm display directly by stepping through the graphic displays or by using an alarm "hot key" (P1,P2,P3, White Alarm) to display a 1 ist of current alarm descriptions and locations. The operator then monitors the status of the alarm through either a graphic or faceplate screen. Conflict may arise when new alarms occur before previous alarm(s) are resolved, and the operator must also view summary displays to better determine the cause and appropriate corrective action to take with respect to the alarm condition(s). In such instances, the operator is placed in a situation that requires integration of discrete sets of information from sources that must be independently accessed.

\section{Recommendation}

Conduct a careful analysis of operations to specifically address those areas, such as workioad and integration of discrete sets of information, that directly impact an operator's performance. This analysis would provide a framework upon which to develop and test operating procedures (based, for 
example, on one versus two versus three operators). Further, operational needs would be clearly defined within a known operational environment. This information could be used as a point of reference to systematically evaluate different staffing levels and the appropriate roles sor each operator using such criteria as safety and cost, and could thus contribute to the development of suitable system hardware/software.

\subsection{ABSENCE OF REMOTE DETECTORS ON EXHAUST FILTERS}

Currently, exhaust filter radiation counts must be monitored localiy. This may increase the operators' potential exposure to radiation, and the time constraints inherent in this process decrease the operators real-time knowledge of the system radiation levels (which is an important diagnostic tool for detection of such items as spray leaks).

\section{Example}

The radiation counts on exhaust filters are not indicated on the MCS system.

\section{Recommendation}

Place remote radiation sensors on the exhaust filters and link them to the MCS system.

\subsection{LACK OF TOXIC LEAK DETECTION MONITORS}

Currently, no monitors in the Evaporator detect the presence of toxic material. Since a great deal of the process material is toxic, the presence of toxic fumes might, in some cases, be a better indicator of contamination (spray leaks, etc.) than radiation. Additionally, of course, operator safety concerns are associated with the undetected presence of toxic materials.

\section{Example}

No information about the presence of toxic material is presented on the MCS system. 


\section{Recommendation}

Install toxic material detection equipment in the Evaporator and link it to the alarm structure on the MCS.

\subsection{COMPLEX PROCESSES REQUIRED TO FIND SOME SPRAY LEAKS}

Some spray leaks require removal of large plates over the Evaporator in order to locate the leaks with the remote cameras. This removal requires the presence of a crane operator, which could seriously delay location and correction of a leak, and may serve to decrease the operator's knowledge of the exact system status. Given the frequent nature of spray leaks, the ability to locate them should be uncomplicated.

Example

See Observation.

Recommendation

Make probable locations for spray leaks as visually accessible as possible, perhaps by remote camera placement. 


\subsection{CONCLUSION}

From this assessment, it is apparent that the safe, efficient operation of the 242-A Evaporator system is paramount in the minds of management, operators, and technical support personnel. Evaporator hardware and software design features do reflect this perspective and, as a result, the system has "user friendly" qualities for providing an operator interface for controlling and monitoring the Evaporator system.

In general terms, many of the items reported herein may stem from Evaporator system development apparently occurring in the absence of a welldefined "Concept of Operations." This Concept of Operation would provide baseline definitions of such system elements as Evaporator hardware and software, the number and role of operators, and the interaction between the operators and the systems. Such a Concept would not only serve as a guide to the development process but, perhaps more importantly, also as a relatively stable foundation from which to consider the numerous changes that have occurred during system development. Simply stated, Evaporator system development has been a very dynamic process (e.g., with respect to degree of automation to be provided) and this has, in effect, created a "moving target" to be hit by system developers, most notably, those responsible for MCS software.

Among other issues, this problem may influence the approach taken for operator training. "On-the-job training" appears to be relied on quite heavily to define operator roles as well as to overcome design shortcomings. As an alternative, it is recommended that system managers, operators, developers, trainers, and human factors experts jointiy develop a Concept of Operations document through which to:

- systematically enhance the evaporator system's control and monitoring hardware and software system

- plan and direct development of an effective training program

- implement the changes recommended herein

- ensure the ease of incorporating desired and required future changes 
- assess the limitations imposed by the Texas Instruments hardware and software.

The MCS system is currently undergoing Operational Test Procedures (OTP) that are identifying many problems with the design of the system, and many of thess items are being passed to the software developers for correction.

The OTP could be used as a tool for reporting, evaluating, and correcting human factors engineering design flaws. Additionally, an approach to problem remediation could be developed inat reflects the collaborative efforts of experts (i.e., operators), software engineers, and human factors experts.

Additionally, the limitations said to be imposed by the Texas Instruments hardware and software package should be assessed further, and the results of this assessment could be used to define requirements for the anticipated upgrades to this system. 


\subsection{REFERENCES}

Smith S. L., and J. N. Mosier. 1986. Guidelines for Designing User Interface Software. ESD-TR-86-278, Defense Logistics Agency, Alexandria, Virginia.

U.S. Department of Defense (DOD). 1989. Military Standard Human Engineering Design Criteria for Military Systems, Equipment and Facilities.

MIL-STD-1472D, Department of Defense, Washington, D.C.

U.S. Department of Defense (DOD). 1984. Military Standard System Safety Program Requirements. MIL-STD-882B, Department of Defense, Washington, D.C.

U.S. Nuclear Regulatory Commission (NRC). 1981. Guidelines for Control Room Design Reviews. NUREG-0700, U.S. Nuclear Regulatory Commission, Washington, D.C. 
APPENDIX

TABLES 


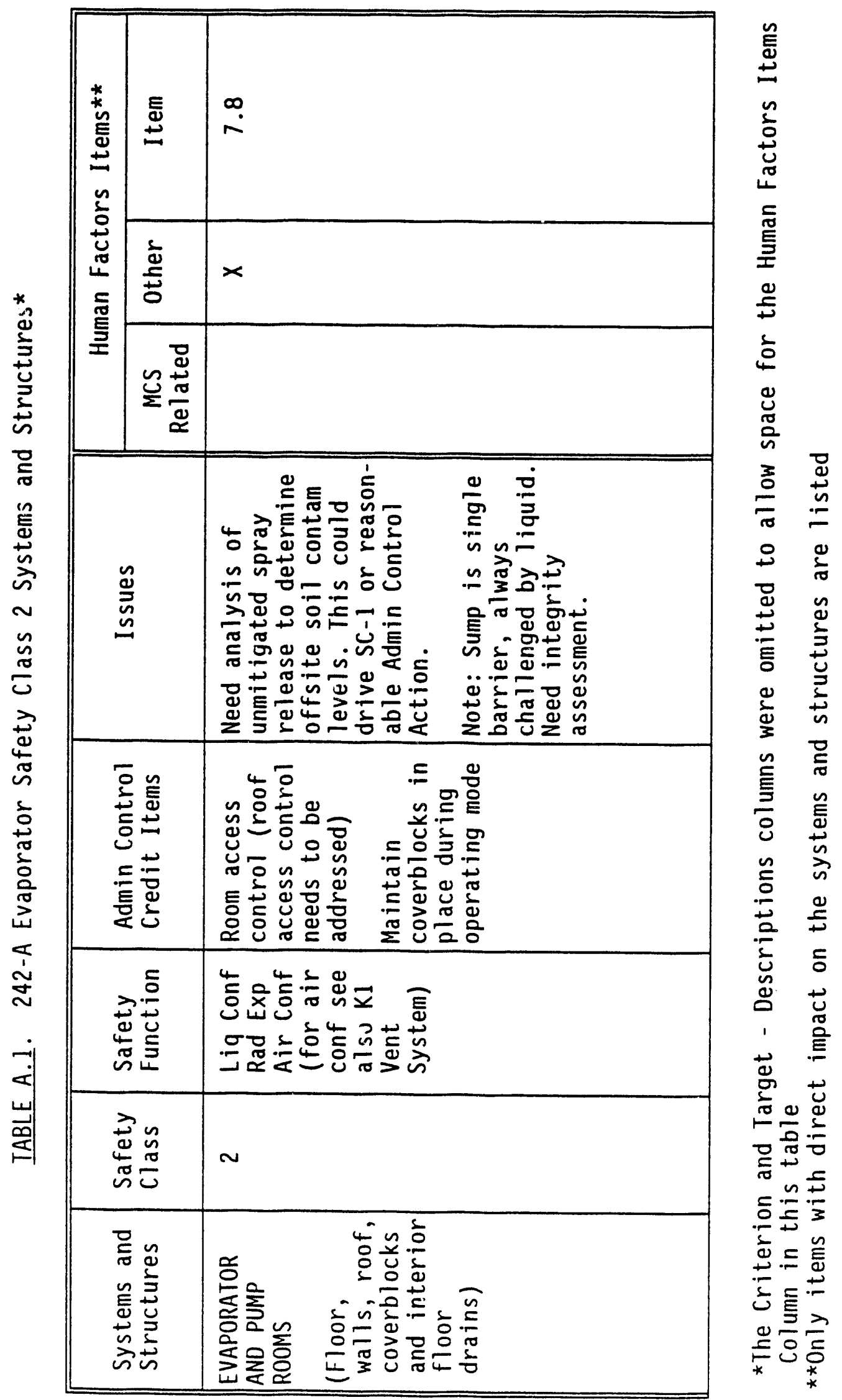

A. 1 


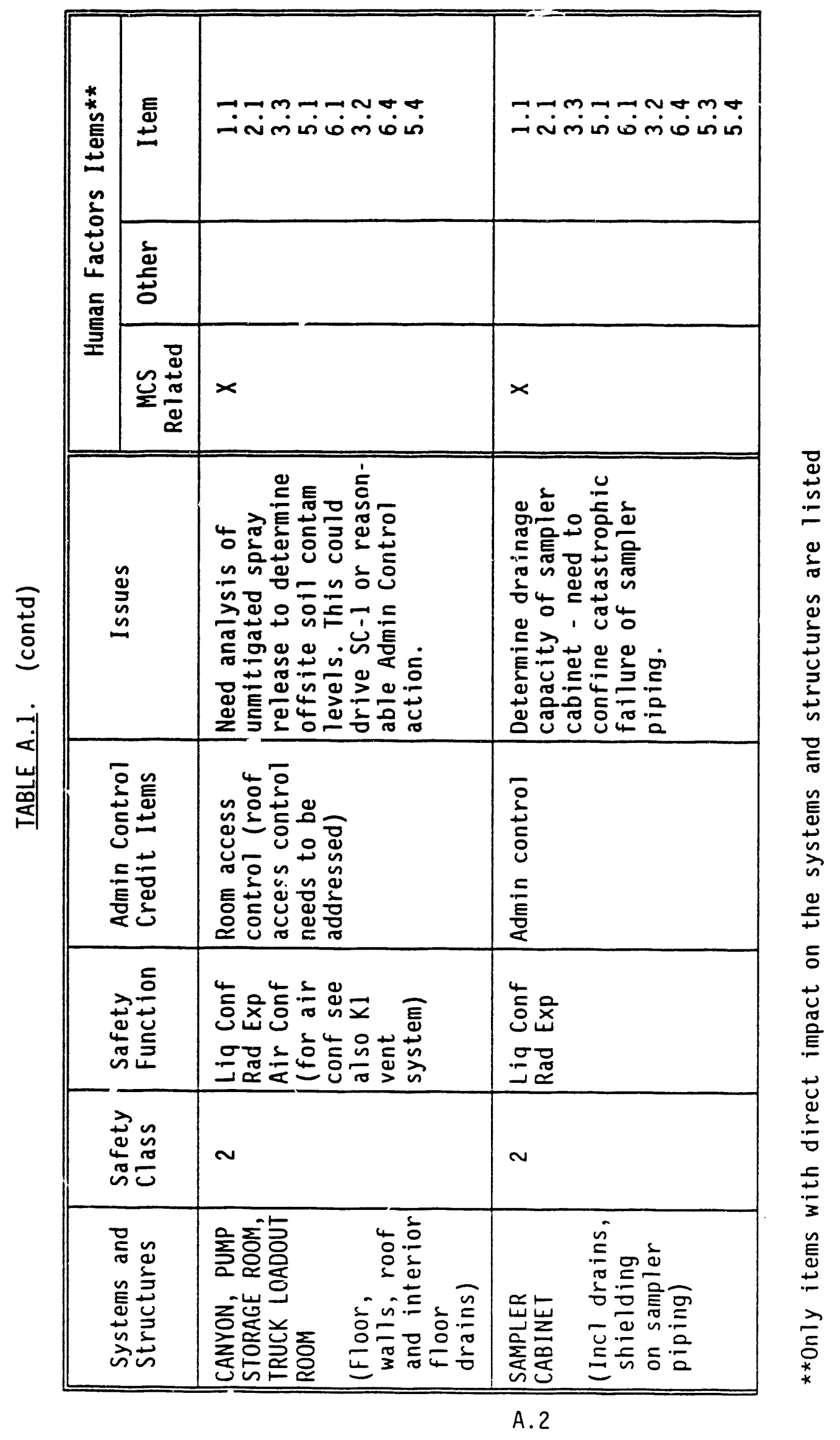




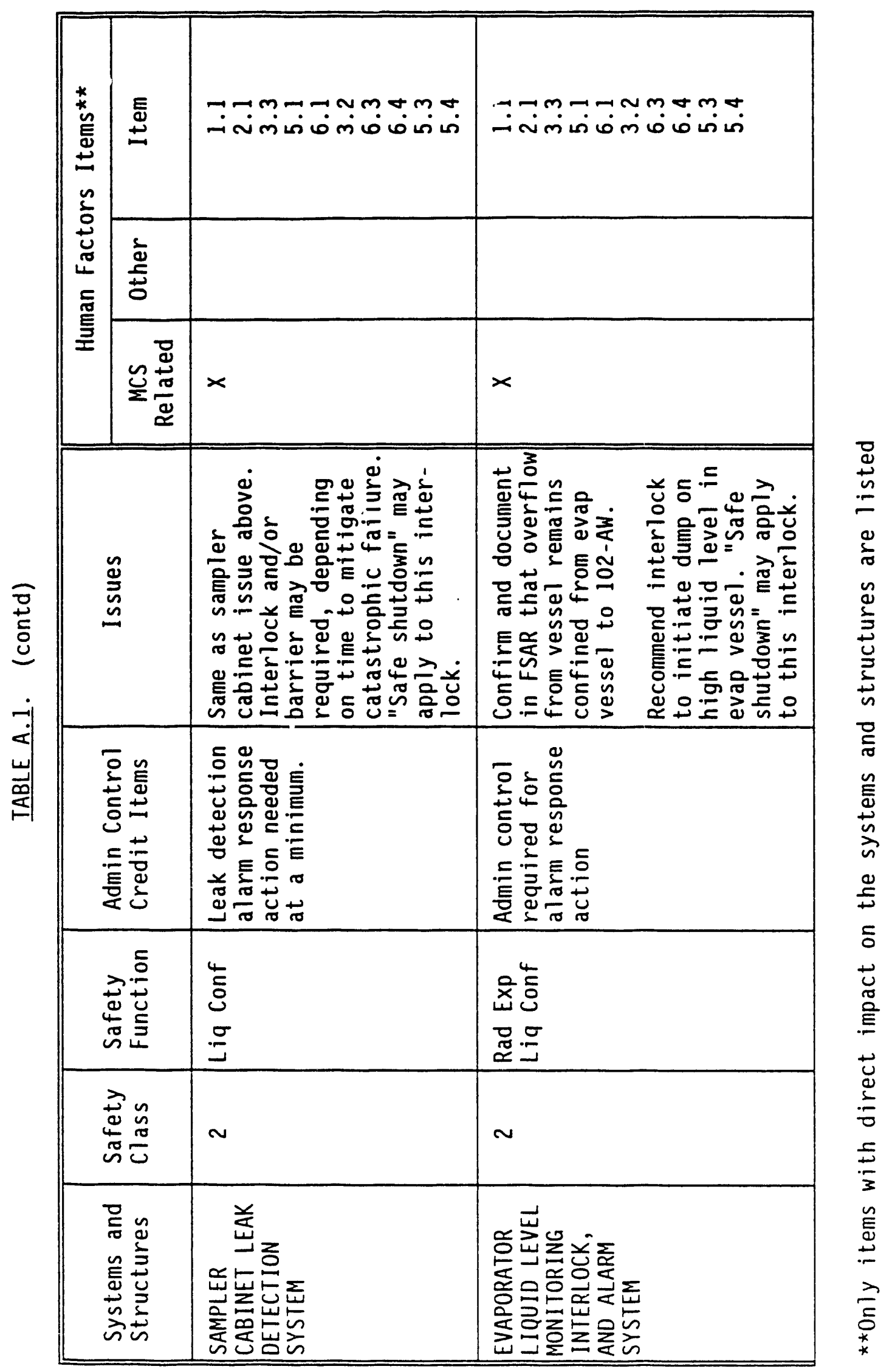

A. 3 


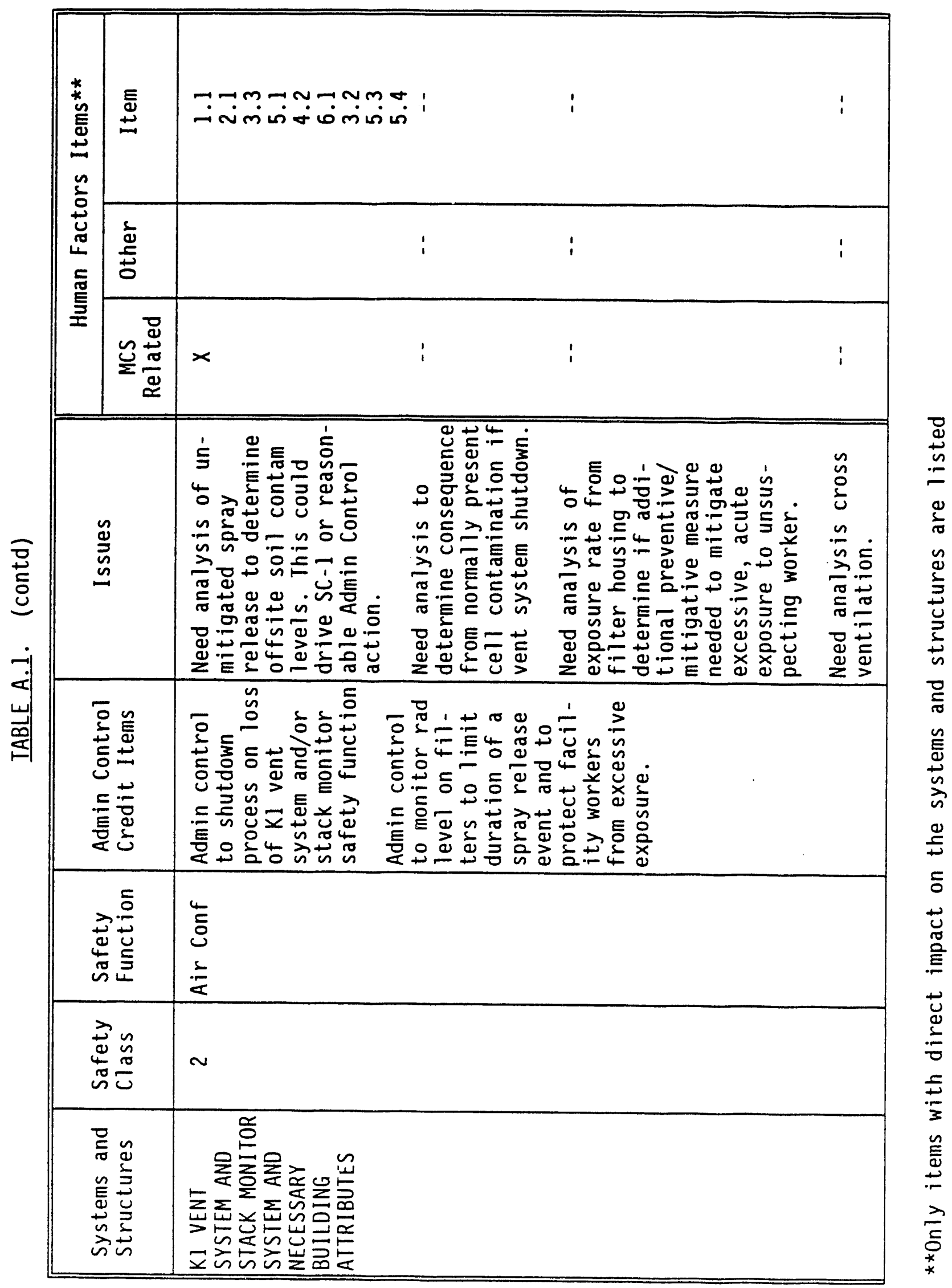

A. 4 


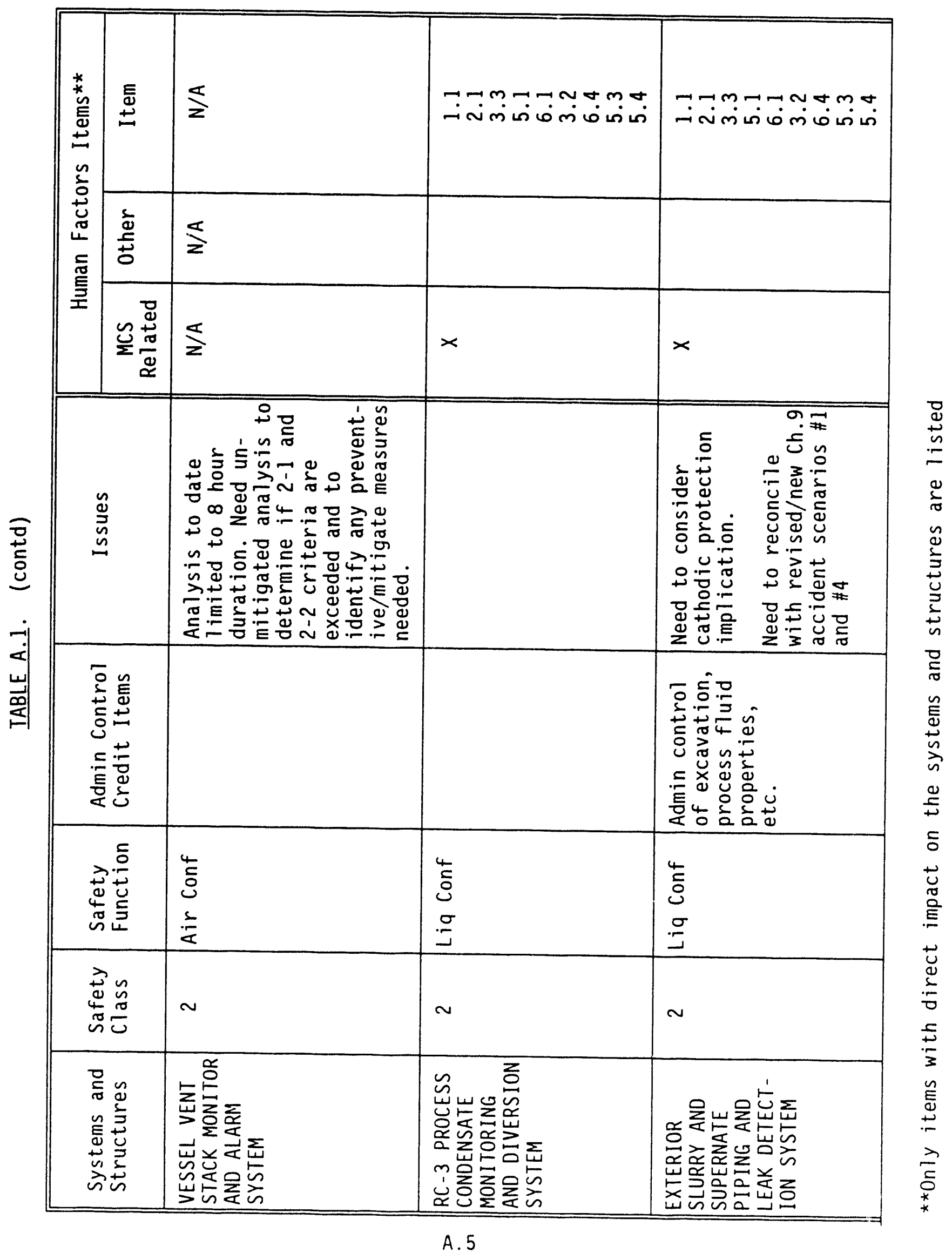




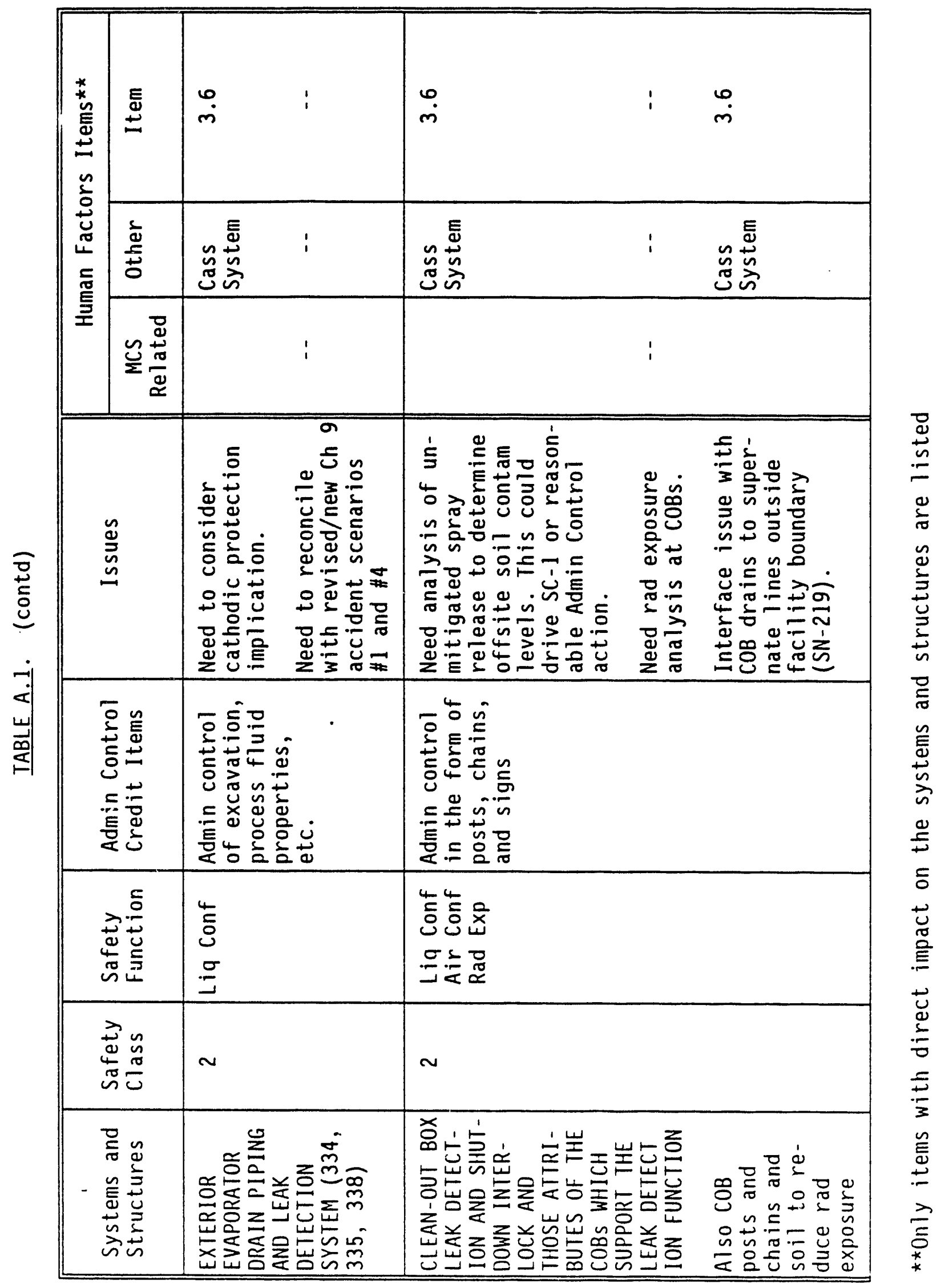

A. 6 


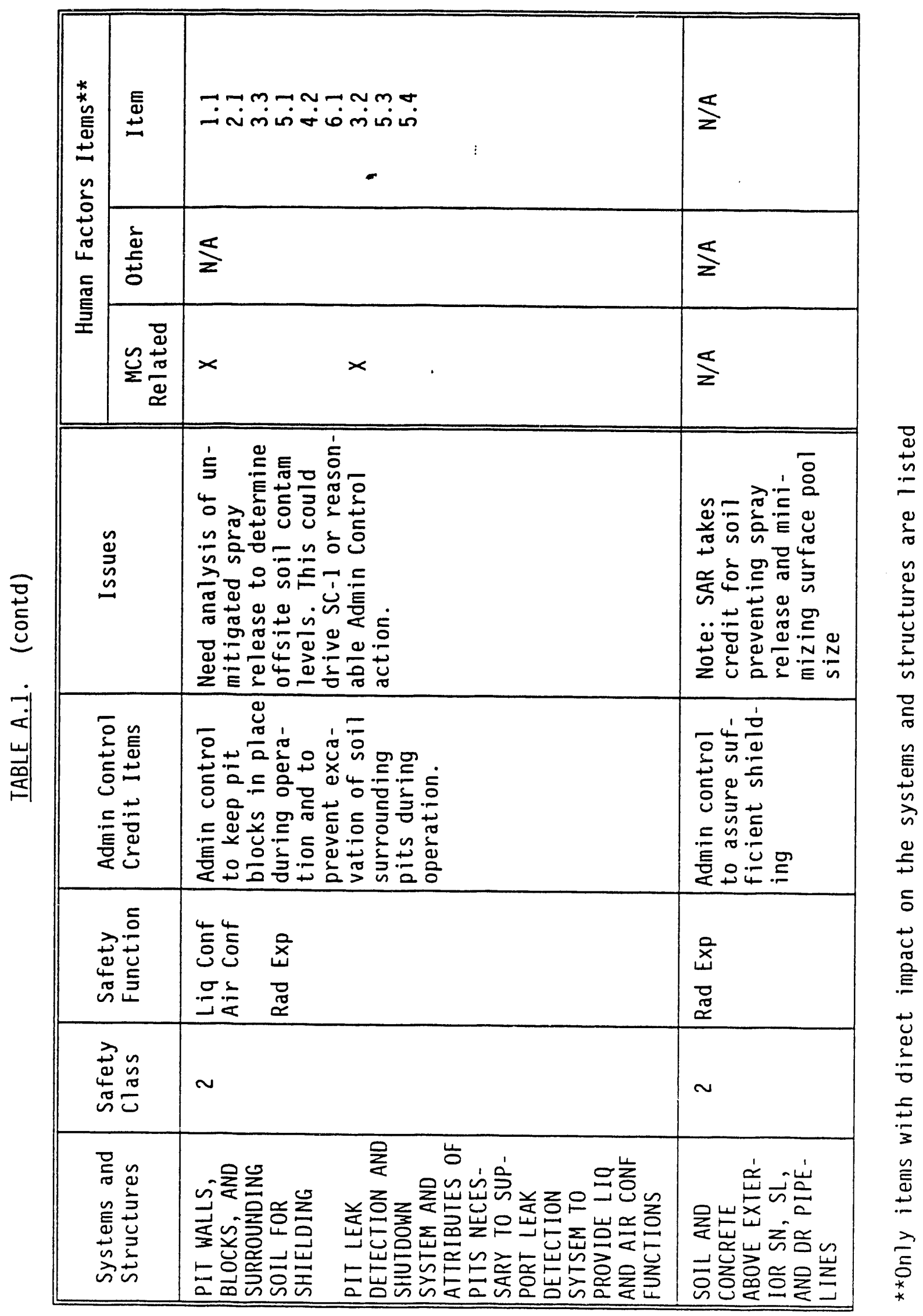

A. 7 


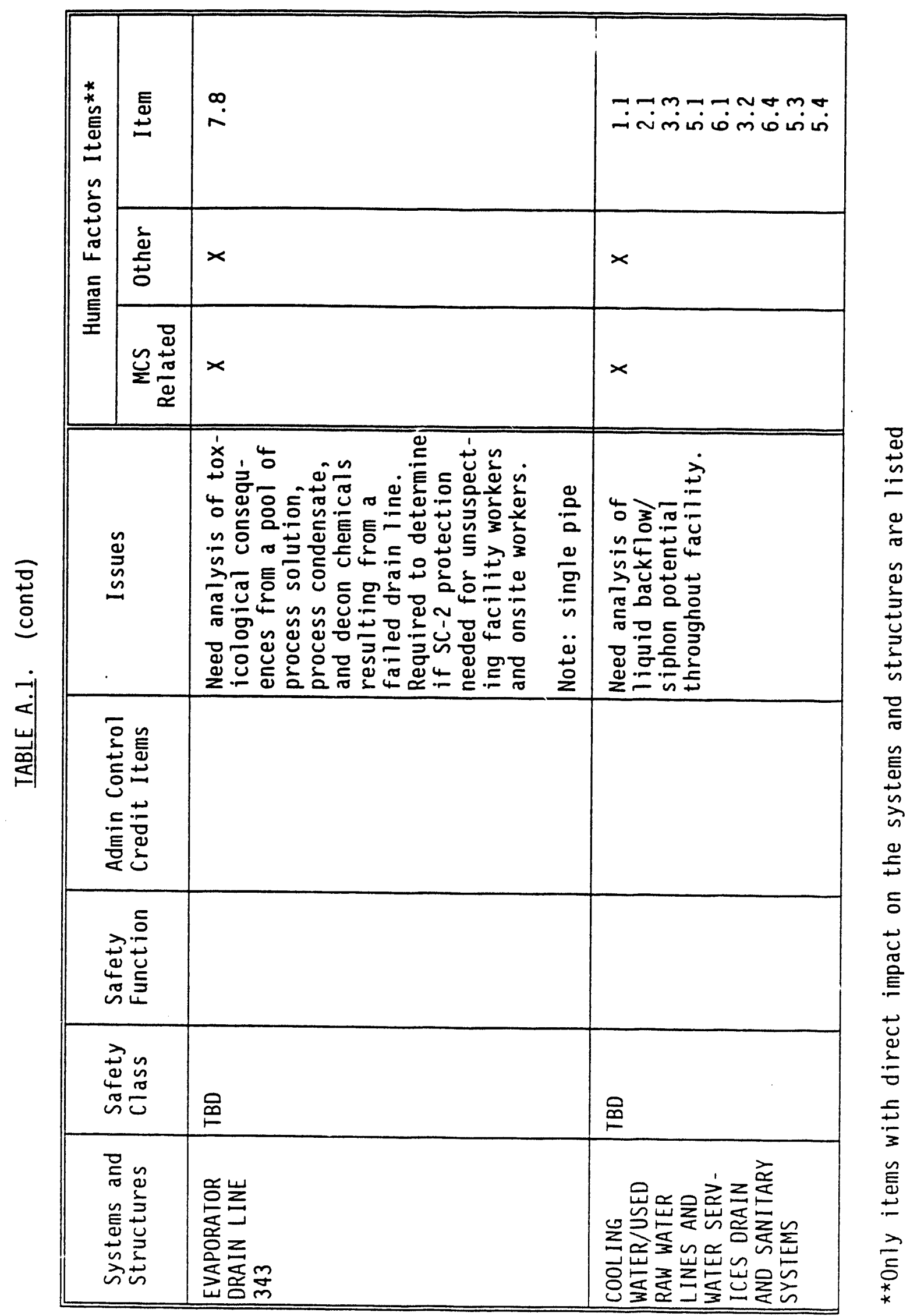

A. 8 


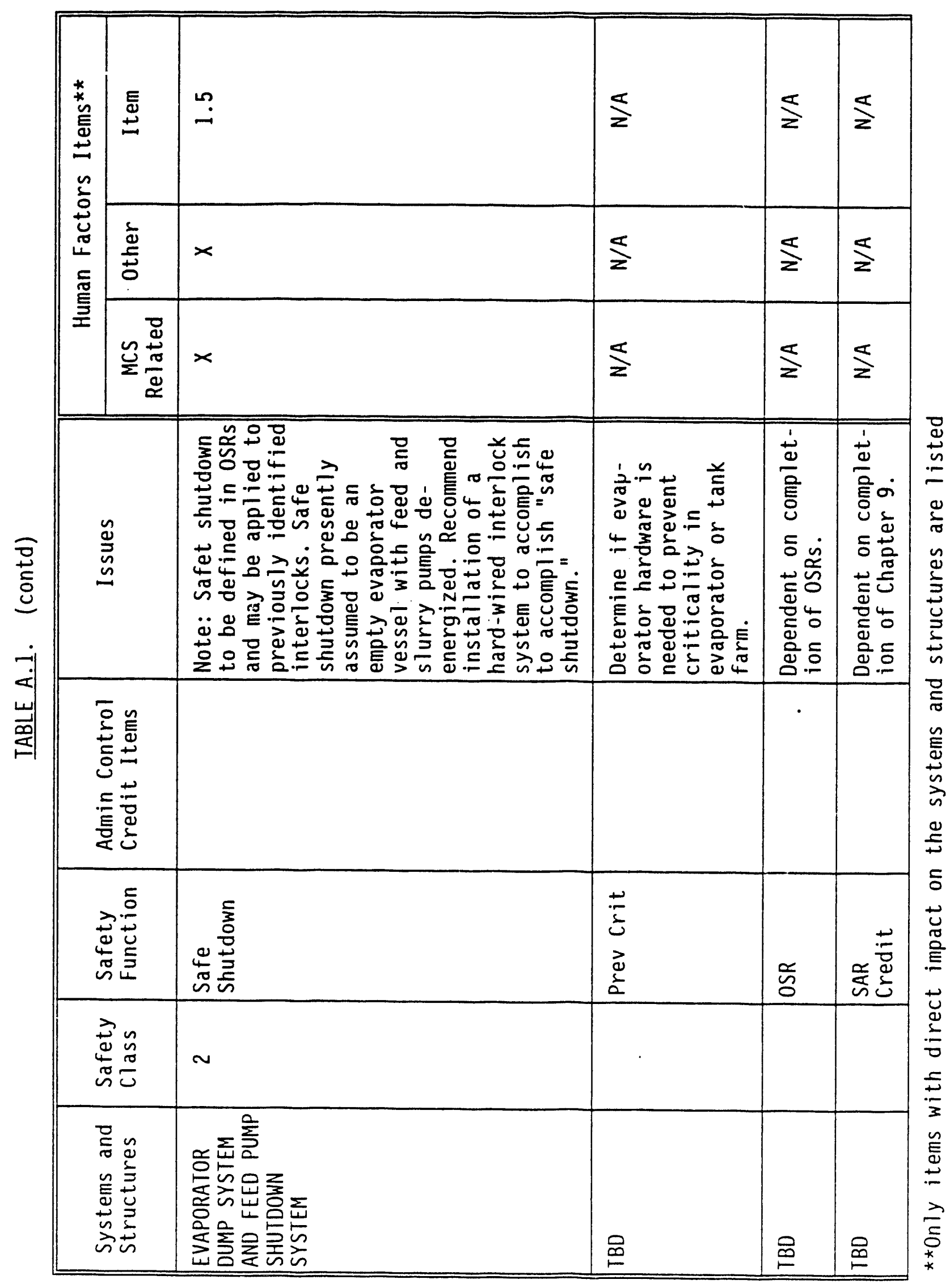

A. 9 


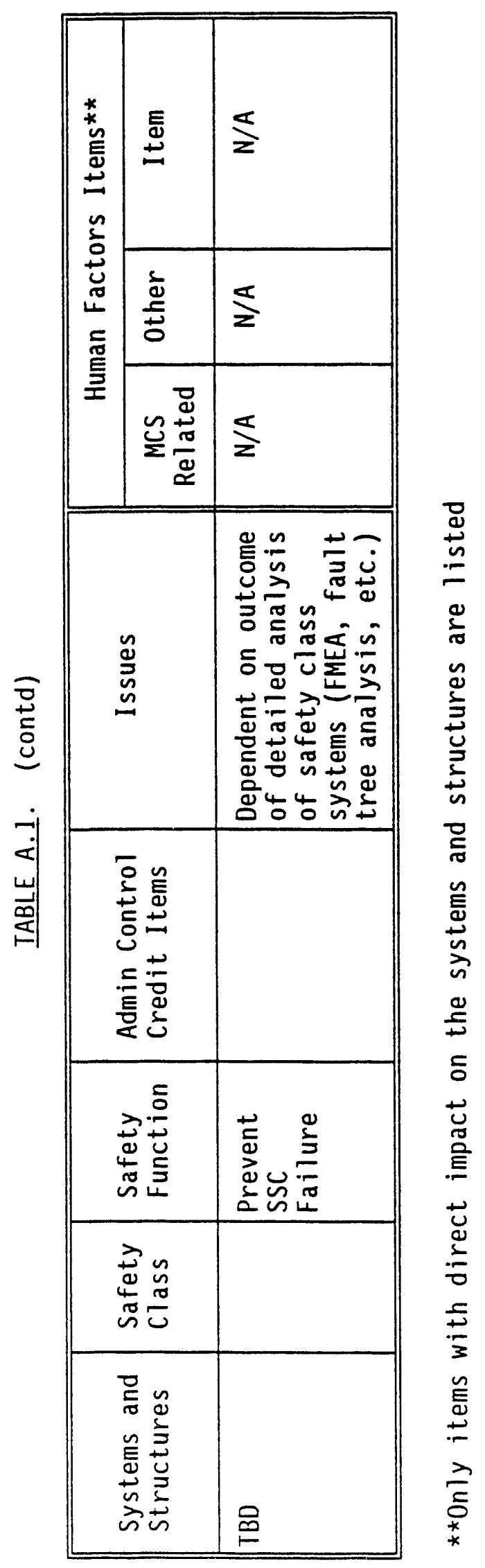

A. 10 


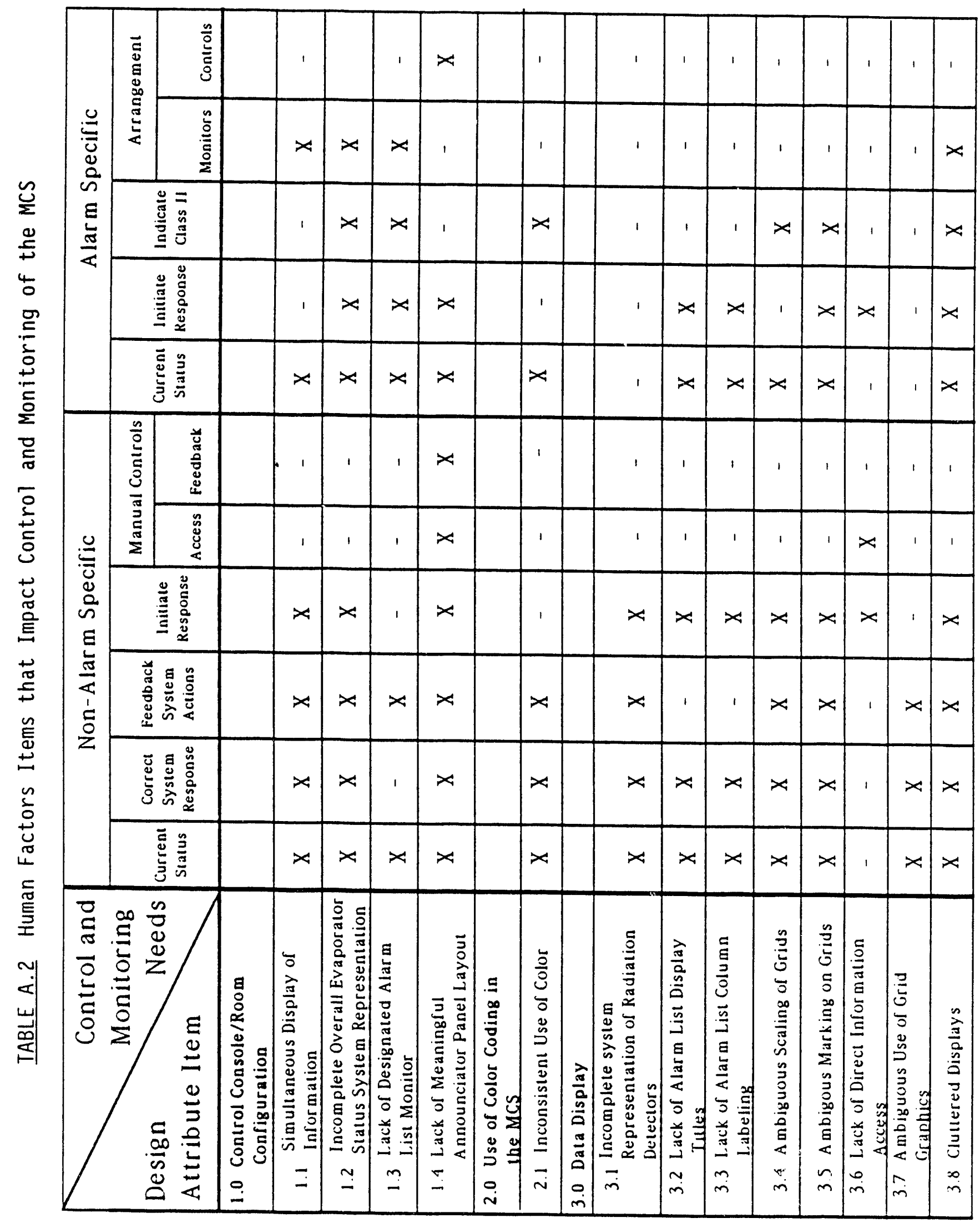

A. 11 


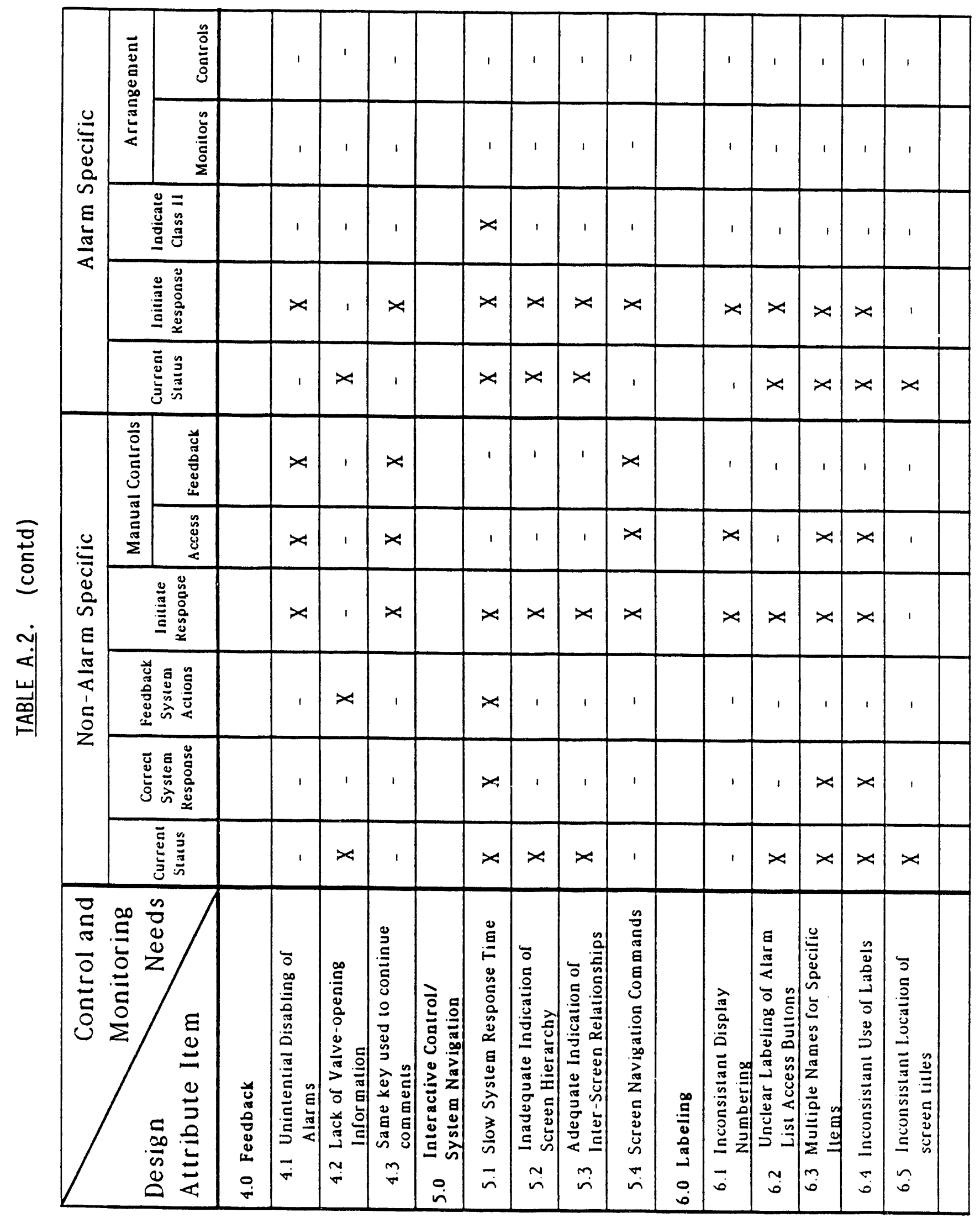

A. 12 


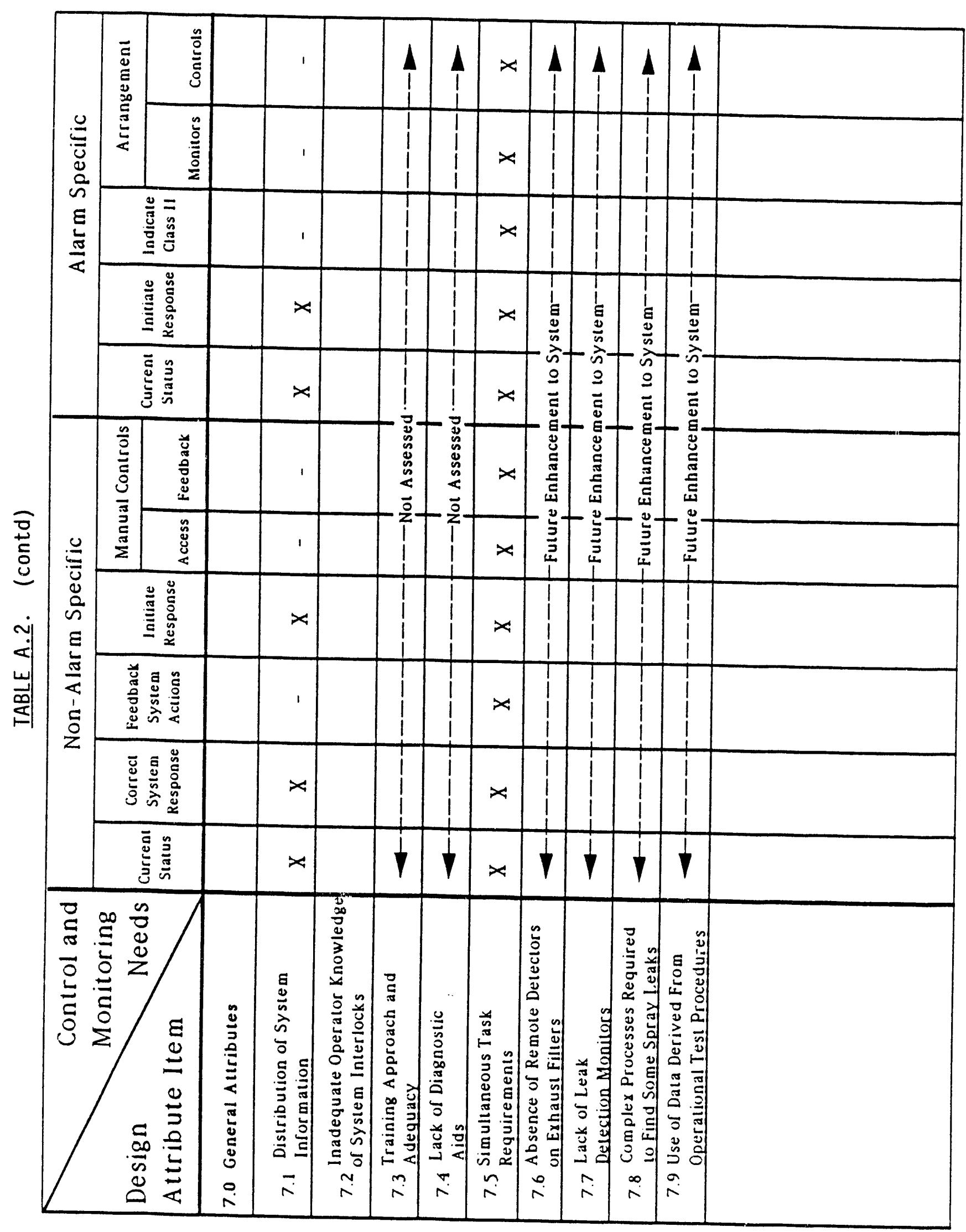

A. 13 


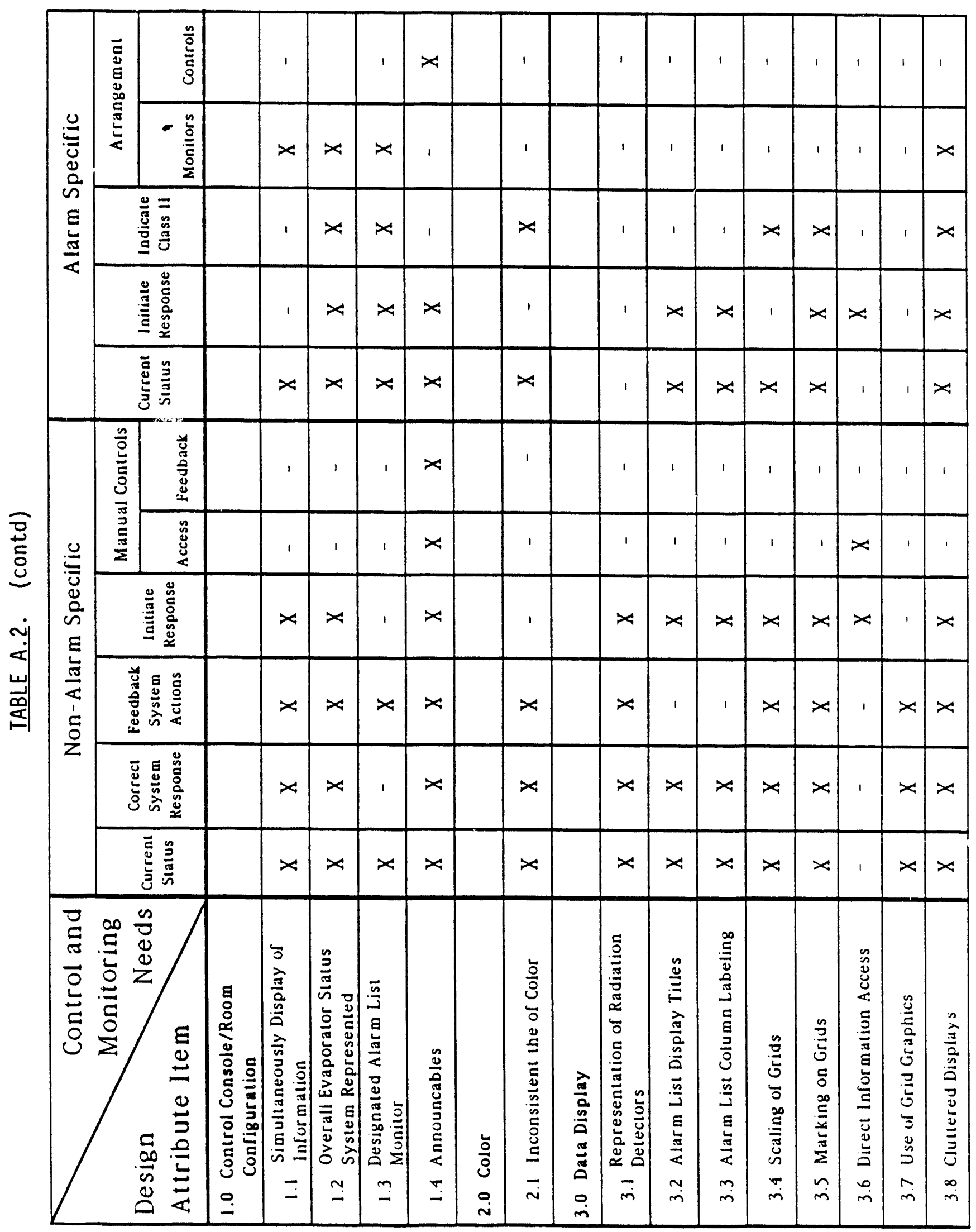

A. 14 


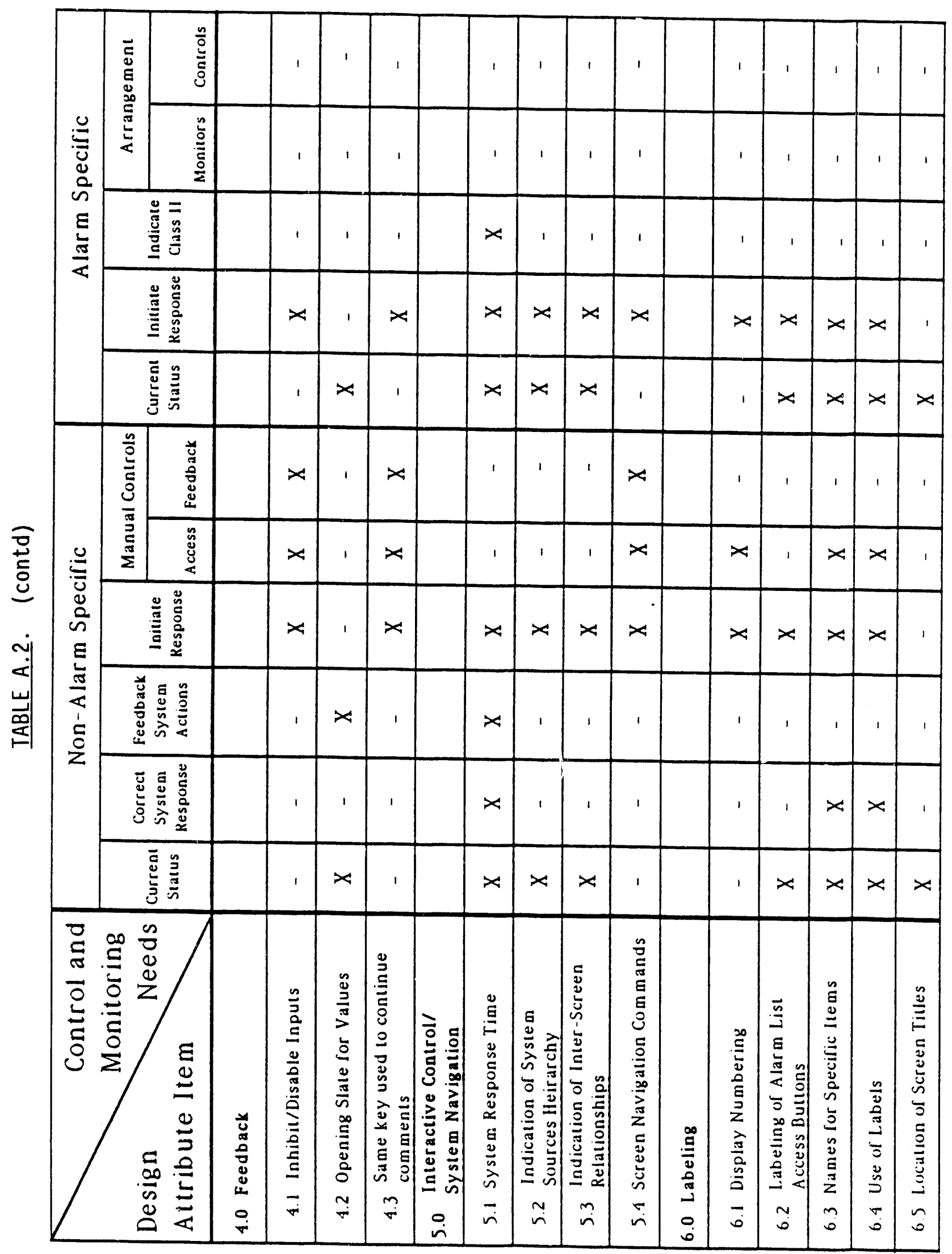

A. 15 


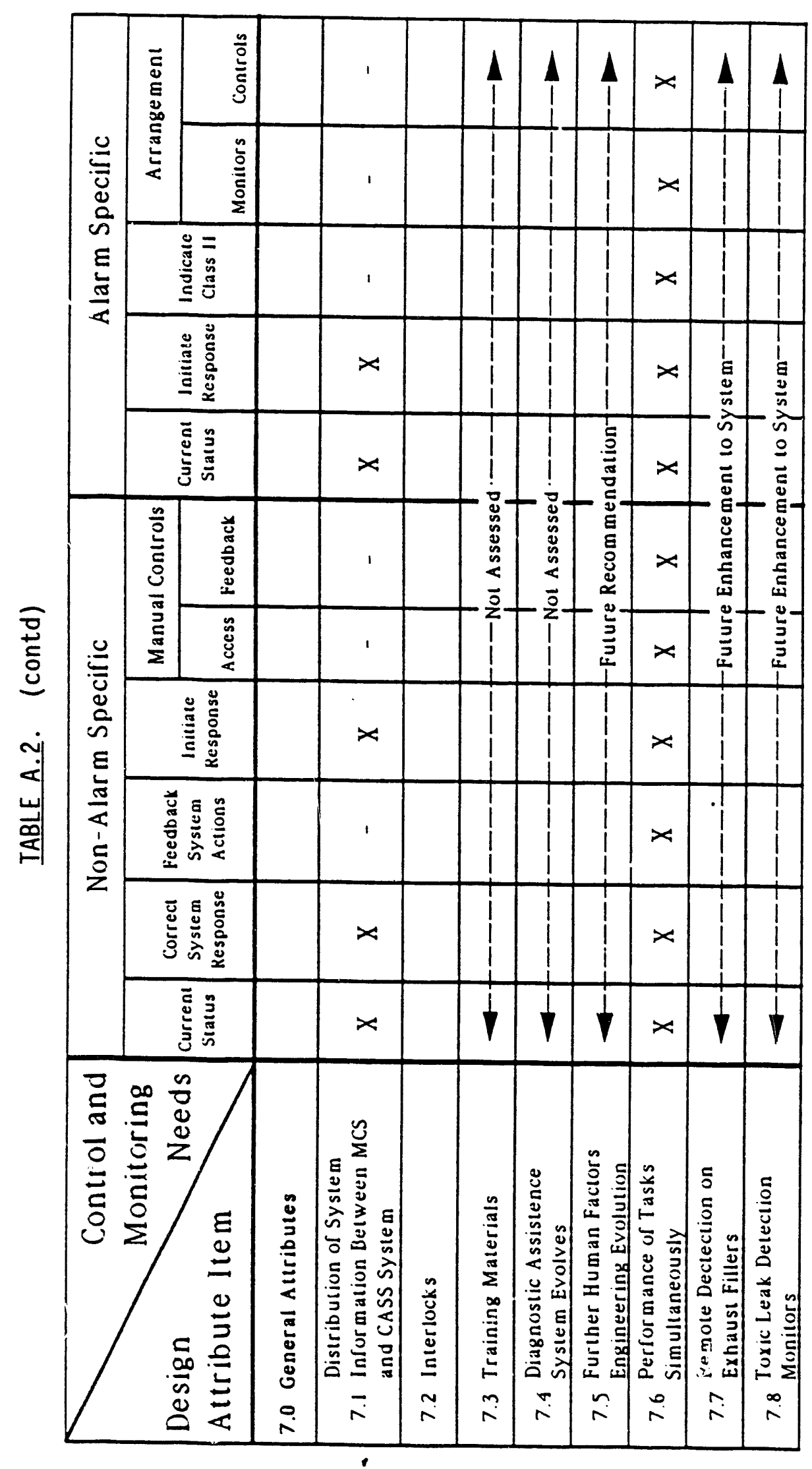

A. 16 
IABLE A.3. Some Methods for Navigating Through the Monitor and Control System

\begin{tabular}{|c|c|c|c|c|c|c|}
\hline METHOD USED Keyboard Key & Arrows & Arrows & Page & Prev & Arrows & $\begin{array}{l}\text { Quick } \\
\text { Acces }\end{array}$ \\
\hline MCS SYSTEM & 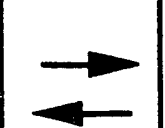 & $\Rightarrow$ & Page & Prev & 4 & $\#$ \\
\hline $\begin{array}{l}\text { Screens } \\
\text { Display associated } \\
\text { graphic }\end{array}$ & $x$ & $x$ & $x$ & $x$ & $x$ & $x$ \\
\hline Display associated text & & & $x$ & $x$ & & $x$ \\
\hline $\begin{array}{l}\text { Displays next page } \\
\text { in sequence }\end{array}$ & $x$ & $x$ & $x$ & $x$ & $x$ & \\
\hline Displays previous page & $x$ & $x$ & $x$ & $x$ & $x$ & \\
\hline $\begin{array}{l}\text { Display continued on } \\
\text { right and/or left }\end{array}$ & $x$ & $x$ & $x$ & $x$ & & \\
\hline $\begin{array}{l}\text { Keyboard } \\
\text { Quick access keys }\end{array}$ & $x$ & $x$ & & & $x$ & $x$ \\
\hline Keypad & & $x$ & & & & $x$ \\
\hline Quick access key/keypad & & $x$ & & & & $x$ \\
\hline
\end{tabular}




\section{DISTRIBUTION}

No. of

Copies

\section{OFFSITE}

2 DOE Office of Scientific and Technical Information

\section{ONSITE}

9 Westinghouse

L. E. Johnson, 65-10 (3)

J. C. Lavender, 65-10 (5)

R. J. Nicklas, Rl-43
No. of

Copies

18 Pacific Northwest Laboratory

M. L. Hirsch, K6-66 (6)

S. T. Hunt, K6-66 (2)

D. J. Pond, K6-66 (2)

A. Schur, K6-66 (2)

Publishing Coordination

Technical Report Files (5) 

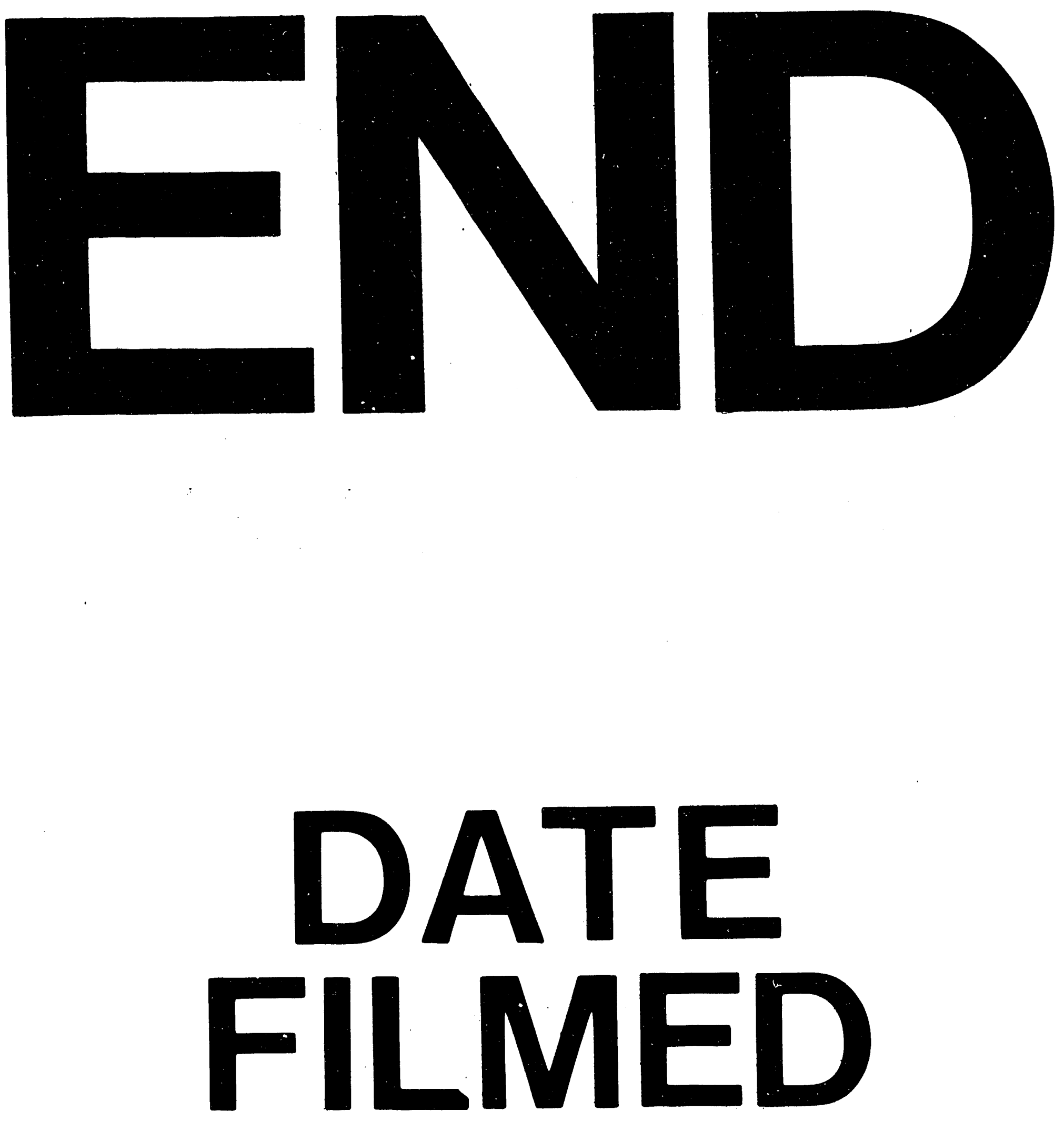

I

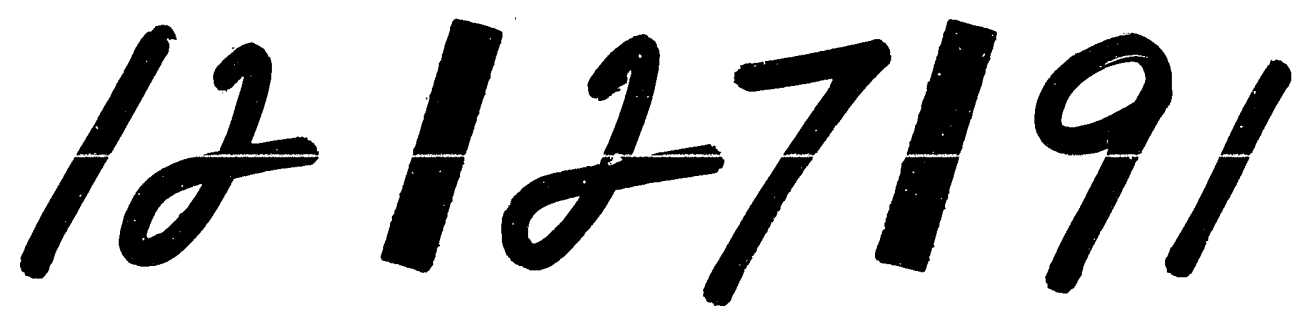


